“This manuscript has been accepted for publication in Science. This version has not undergone final editing. Please refer to the complete version of record at http://www.sciencemag.org/. The manuscript may not be reproduced or used in any manner that does not fall within the fair use provisions of the Copyright Act without the prior, written permission of AAAS."

\title{
The evolution of infanticide by males in mammalian societies
}

10

\author{
Dieter Lukas $^{1, *}$ \& Elise Huchard ${ }^{1,2}$
}

\section{Affiliations:}

$15{ }^{1}$ LARG, Department of Zoology, University of Cambridge, Downing Street, Cambridge, CB2 3EJ.

${ }^{2}$ CEFE UMR 5175, CNRS - Université de Montpellier, 1919 Route de Mende, 34293 Montpellier Cedex 5, France

20

* Corresponding author:

Dieter Lukas

LARG - Department of Zoology

University of Cambridge

25 Downing Street

Cambridge CB2 3EJ

Email: d1384@cam.ac.uk

30 Short title: The evolution of male infanticide in mammals 


\begin{abstract}
.
Male mammals may commonly kill conspecific offspring. The benefits of such infanticide to males, and its costs to females, likely vary across mammalian social and mating systems. Here 35 we use comparative analyses to show that infanticide primarily evolves in social mammals where reproduction is monopolized by a minority of males. It has not promoted social counter-strategies such as female gregariousness, pair-living, or changes in group size and sex-ratio but is successfully prevented by female sexual promiscuity, a paternity dilution strategy. These findings indicate that infanticide is a consequence, rather than a cause, of

40 contrasts in mammalian social systems affecting the intensity of sexual conflict.
\end{abstract}

\title{
One Sentence Summary
}

45 Infanticide by males is an evolutionary consequence, rather than a cause, of contrasts in mammalian social systems and reflects the intensity of sexual conflict.

Keywords: infanticide, mammals, phylogeny, social system, mating system, reproductive

50 skew, dominance tenure, polyandry 


\section{Main text}

Infanticide by males is widespread in mammals and may represent the main cause of infant mortality in some populations (1). It has long been viewed as a sexually selected strategy that increases mating opportunities for killer males by shortening postpartum infertility in the victim's mother $(2,3)$. This is supported by natural observations across taxa showing that males target unrelated infants and often impregnate the victim's mother afterwards $(1,3,4)$. Attempts to explain the taxonomic distribution of infanticide have however been mainly limited to investigations of the life-history correlates of male infanticide (5-8), showing that it rarely occurs where it does not accelerate the mother's return to sexual activity, as in seasonal

60 breeders who cannot resume cycling before the next breeding season (8).

Several scenarios have linked the distribution of infanticide across species to the evolution of social organization and mating systems in mammals, and they remain largely untested or disputed $(9,10)$. According to the sexual selection hypothesis, the distribution of infanticide is

65 expected to be modulated by contrasts in social systems that affect the intensity of male intrasexual competition $(3,5,8)$. Male infanticide should thus be prevalent in species where a few males mate with multiple females and monopolize most reproductive opportunities. However, females may respond to infanticide by developing counter-strategies that may refine patterns of associations across species. Social counter-strategies may include the evolution of

70 female sociality $(6,11,12)$, of permanent male-female associations (13-15), or of changes in the group sex-ratio $(6,11,12,15)$ because females may form coalitions with other females or with resident males to defend their progeny against male invaders. Additionally, females may mate with multiple partners to confuse paternity and dissuade infanticide $(6,16,17)$, which may thus be absent in species with pronounced sperm competition. The evolutionary arms

75 race between the sexes driven by male infanticide has generated confusion and controversy regarding the role of infanticide in the evolution of mammalian societies, calling for more integrative studies.

Here we use information gathered on 260 mammal species including 119 species with, and 80141 without infanticide (Figure 1) to identify how variation in social organization and mating systems may have favoured or prevented the evolution of infanticide by males using phylogenetic analyses (18). Specifically, we test if infanticide has primarily evolved in species where females breed throughout the year and some males have high reproductive monopoly, and if it has selected for social and sexual counter-strategies, including transitions towards 
85 female gregariousness, permanent male-female associations, changes in group size or sexratio or increases in female sexual promiscuity. We included infanticide records from wild populations for which the killer was unambiguously identified as an adult male. Species for which infanticide had never been observed were included only if natural observations on females and juveniles were available over more than 3 reproductive seasons, to minimize the

90 risk of misclassifying them as "non-infanticidal". The phylogenetic relatedness between species was inferred from the updated mammalian supertree (19) and analyses were also replicated in primates exclusively, which confirmed results obtained across mammals (see supplementary results).

95 The distribution of male infanticide is closely associated with the absence of seasonal or 'annual' breeding (defined as an average inter-birth interval of 360-370 days). Infanticide occurs in a majority of non-annual breeders ( $76 \%$ of 97 species), compared to $28 \%$ of 134 annual breeders (lambda $=0.67, \mathrm{t}=-4.0, \mathrm{p}<0.001$ ). A long lactation (relative to gestation) and the absence of a postpartum oestrus, two life-history traits affecting the time to cycling

100 resumption in mothers of killed infants, are also associated with male infanticide, though their association disappears when controlling for annual breeding (for both traits, $\mathrm{p}$ as estimated by MCMCglmm (pMCMC) $>0.08$ while pMCMC for annual breeding $<0.001$ ). While previous studies have used the ratio of the duration of lactation to that of gestation to estimate infanticide risk (6-8), our results reveal that this association is weak: lactation exceeds 105 gestation in 25 of 45 mammal species with infanticide, and in 38 of 89 species without infanticide. Other aspects of life-history were not associated with male infanticide (longevity: $\mathrm{n}=210$ species, $\mathrm{pMCMC}=0.08$; litter size: $\mathrm{n}=230$ species, $\mathrm{pMCMC}=0.07$; relative offspring weight at birth: $\mathrm{n}=191$ species, $\mathrm{pMCMC}=0.59$ ), suggesting that infanticide evolution is not determined by a species' pace of life. Overall, the possibility for females to breed throughout

110 the year is the only life-history trait examined that significantly explains the distribution of infanticide, confirming previous work and suggesting that infanticidal males gain extra mating opportunities due to earlier cycle resumption of the victim's mother in non-annual breeders. Such males are thereby redirecting maternal investment from unrelated offspring towards their own future offspring.

115

Comparing the occurrence of male infanticide across social systems, we find that males commit infanticide more frequently in stable mixed-sex groups (66\% of 112 species) than in solitary species $(40 \%$ of 78 solitary species, $\mathrm{pAN}=0.01)$, in species with female-only groups 
( $23 \%$ of 31 species, $\mathrm{pAN}=0.006)$ and in pair-living species $(18 \%$ of 39 species, $\mathrm{pAN}<0.001)$.

120 Phylogenetic reconstructions confirm that variation in social organization is a key determinant of the evolution of male infanticide, which is more likely in stable bisexual groups than in any other social system (see supplementary table 1). In addition, social groups contain, on average, 1 male per 2.5 females in species with male infanticide ( $\mathrm{SD}=1.7, \mathrm{n}=56$ species), but only 1 male for 1.3 females in species without infanticide $(\mathrm{SD}=3.2, \mathrm{n}=19$ species, Figure $2 \mathrm{a}$;

125 lambda $=0.47, \mathrm{t}=-3.3, \mathrm{p}=0.002$; this is not an effect of differences in group sizes, as group size is similar in both sets of species: $\mathrm{p}=0.28$ ). Phylogenetic reconstructions suggest that a biased group sex-ratio is a determinant, rather than a consequence, of the evolution of male infanticide: the strongest female biases are observed just before or at the transition towards male infanticide, while there are few or no subsequent changes once infanticide has evolved

130 (see supplementary results).

In line with this, infanticide occurs more frequently where reproduction is monopolized by a few males (Figure 2b): the median percentage of offspring sired by the alpha male is $67 \%$ $(\mathrm{SD}=19.9, \mathrm{n}=15$ species $)$ in species with infanticide, compared to $35 \%(\mathrm{SD}=22.2, \mathrm{n}=5)$ in 135 species without (lambda $=0.75, \mathrm{t}=3.9, \mathrm{p}=0.001$ ). Finally, males retain their dominant position for shorter durations in species with infanticide (Figure 2c): on average, dominance tenure covers two inter-birth intervals (if the females were to successfully wean each litter) $(\mathrm{SD}=1.0$, $\mathrm{n}=34$ species), compared to four in species without infanticide $(\mathrm{SD}=1.2, \mathrm{n}=6)$ (lambda=0.0, $\mathrm{t}=-3.4, \mathrm{p}=0.001)$. These correlations hold after controlling for the effect of annual breeding, 140 which may also affect male ability to monopolize females (Supplementary Table 2). Overall, these findings indicate that a high male monopolization potential favours transitions towards infanticide by allowing males to maximize their reproductive output in systems where the costs of holding dominance shorten their breeding tenures $(20)$.

145 Male infanticide has been proposed to alter social evolution by favouring female gregariousness or permanent male-female associations or by promoting a higher number of resident males that may help mothers to protect their infants from male intruders. We found no support for any of these scenarios. Infanticide risk is low in solitary species, the ancestral mammalian social organization (9), and as such is unlikely to motivate evolutionary

150 transitions from a solitary lifestyle to other social organizations. Phylogenetic reconstructions confirm that male infanticide is significantly more likely to evolve after transitions towards group-living than in their solitary ancestors (see above). The presence of male infanticide 
does not increase the likelihood of a transition from solitary living to social monogamy, to female gregariousness or to group living (see supplementary table 1). In addition, among 155 species living in stable bisexual groups, male infanticide is not linked to changes in the degree of female sociality (5.5 \pm 5.1 females per group in 56 infanticidal species compared to $8.9 \pm 4.0$ in 13 non-infanticidal species; $\mathrm{pMCMC}=0.93$ ). These findings indicate that infanticide by males did not trigger important transitions in mammalian social evolution. Population studies have nevertheless highlighted relationships between infanticide rates and group size (e.g., 21),

160 suggesting that the social consequences of infanticide may differ within populations versus across species, or that selection exerted by infanticide is insufficient at inducing major shifts in mammalian social organization.

Infanticide risk may also lead to the evolution of sexual counter-strategies by females, who might prevent infanticide by mating with many males to dilute paternity $(6,16,17)$. To test this hypothesis, we investigated evolutionary relationships between infanticide and testis size, an indicator of the intensity of sperm competition $(22,23)$. In support of the paternity dilution hypothesis, phylogenetic reconstructions indicate that relative testis size is larger in lineages in which more time has elapsed since the evolution of infanticide. State-dependent diversification models (24) show that increases in testis size follow rather than precede transitions to infanticide as they are not detected on branches immediately before transitions to infanticide, suggesting that infanticide exerts directional selection on relative testis size (18). In addition, infanticide is subsequently lost in lineages where testes have grown large (Figure 3; pMCMC $=0.02$; see supplementary results), indicating that infanticide may 175 disappear where female attempts to prevent male sexual monopolization are successful.

Our findings support key predictions of the sexual selection hypothesis: males primarily kill the offspring of rivals in stable bisexual groups where a few males monopolize reproduction over short periods. Increased testis size following evolutionary transitions to infanticide and 180 secondary loss of infanticide in species with large testes suggests that female paternity dilution strategy efficiently reduces infanticide risk, and emphasizes the reversible nature of infanticide, which may appear and disappear according to the evolutionary arms race between the sexes. While past studies failed to find comparative evidence for sexual counterstrategies to infanticide $(7,16)$, our sample spanning all mammals, combined with phylogenetically 185 controlled analyses, and our focus on testis size to index female sexual promiscuity may explain divergent results. 
Our analyses build on five decades of field observations to understand the distribution of species differences in the occurrence of infanticide by males across mammalian societies. The evolution of infanticide is largely determined by variation in the intensity of male-male contest competition and has not promoted major switches in mammalian social organization. However, it has impacted the evolution of mating systems by increasing female sexual promiscuity as a paternity dilution strategy. These findings suggest that the distribution of infanticide across mammals is a consequence of contrasts in social and mating systems, and closely reflects variation in the intensity of intra- and inter-sexual conflict.

\section{Acknowledgements}

We are grateful to Tim Clutton-Brock, Peter Kappeler, Guy Cowlishaw, Dan Blumstein and an anonymous reviewer for helpful comments on an earlier draft of this manuscript, and to LARG for insightful discussions. DL received funding from the European Research Council 200 (grant N²94494-THCB2011) and EH from the Natural Environment Research Council (grant number NE/RG53472). Data supporting this study are available in the Supplementary Materials.

\section{Figure legends}

\section{Figure 1: Distribution of male infanticide across mammals}

Male infanticide has been reported for about half of all species in our sample (open circles) and seems to have evolved independently multiple times. It mostly occurs in social (dark grey branches), less in solitary (light grey branches), and least in monogamous species (black branches). Animal drawings are from phylopic.org (for full credit see (18)).

\section{Figure 2: Infanticide is associated with polygynous mating systems}

Male infanticide occurs in species in which (a) social groups contain more females per male, (b) dominant males obtain a higher share of reproduction in a given season, but (c) maintain

215 their dominant position for shorter periods (here measured as the average number of interbirth intervals).

\section{Figure 3: Loss of male infanticide occurs in species with large testes}

In some lineages in which males commit infanticide, testes appear to increase in size (relative to body mass) and subsequently, male infanticide is lost when testes are relatively large. 
Figure 1

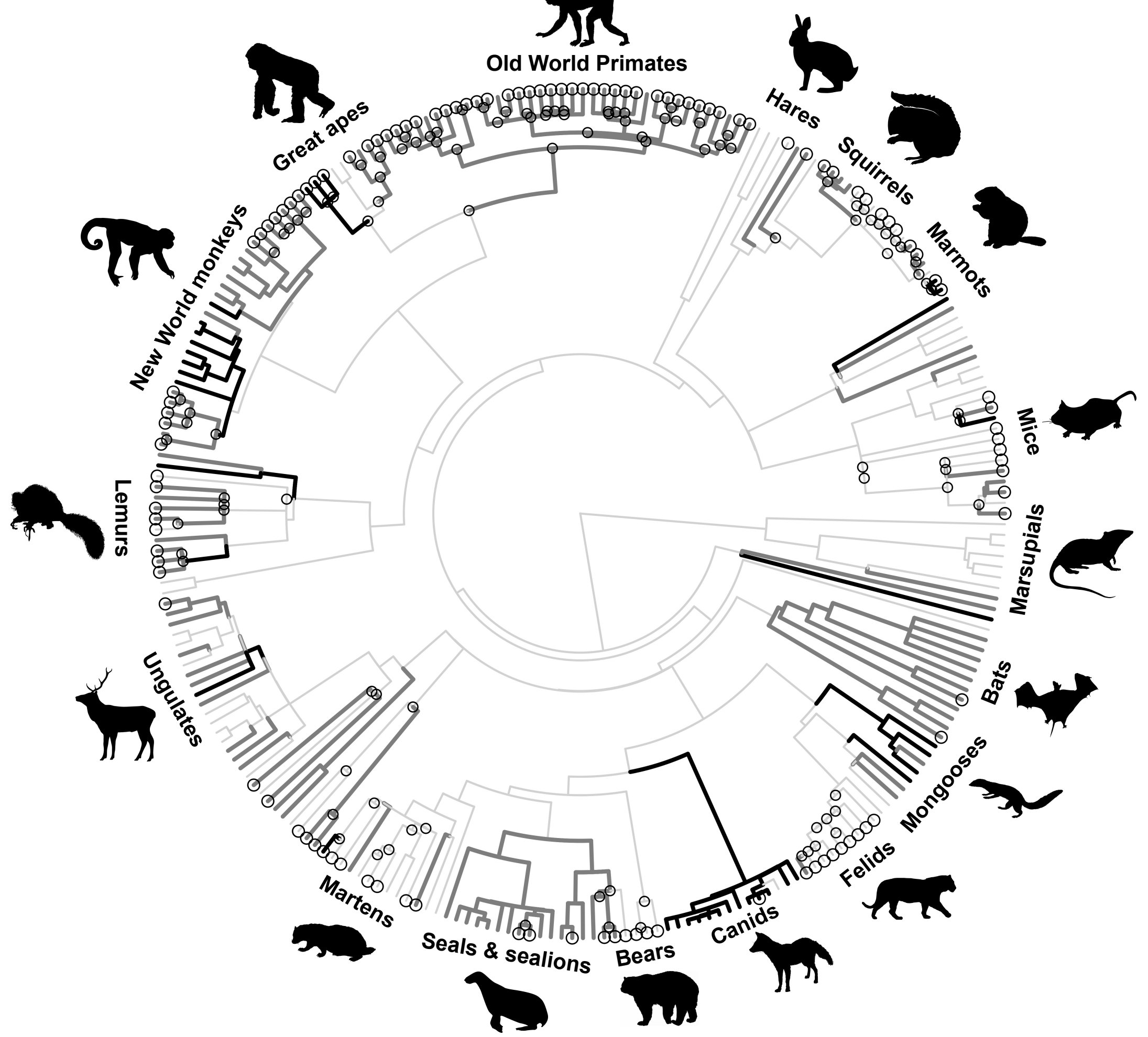


(b) Reproductive skew

No Infanticide Infanticide

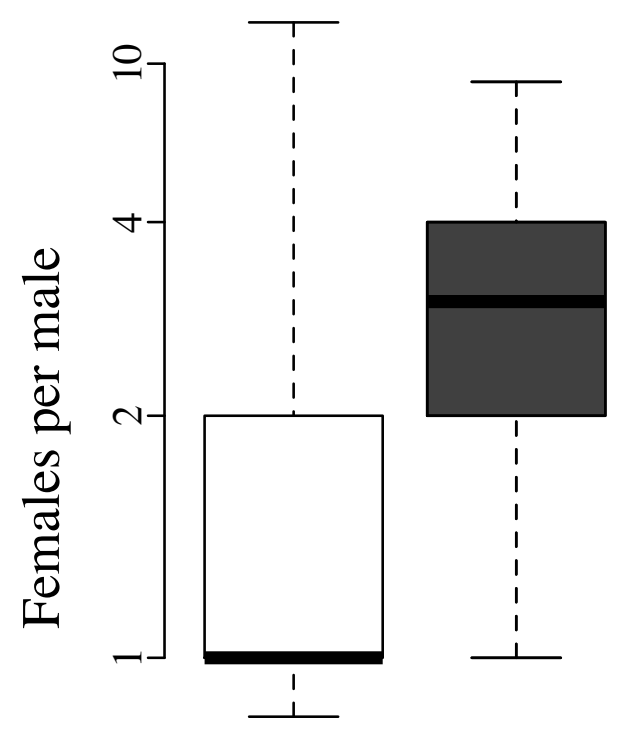

$\mathrm{n}=26$ species
No Infanticide Infanticide

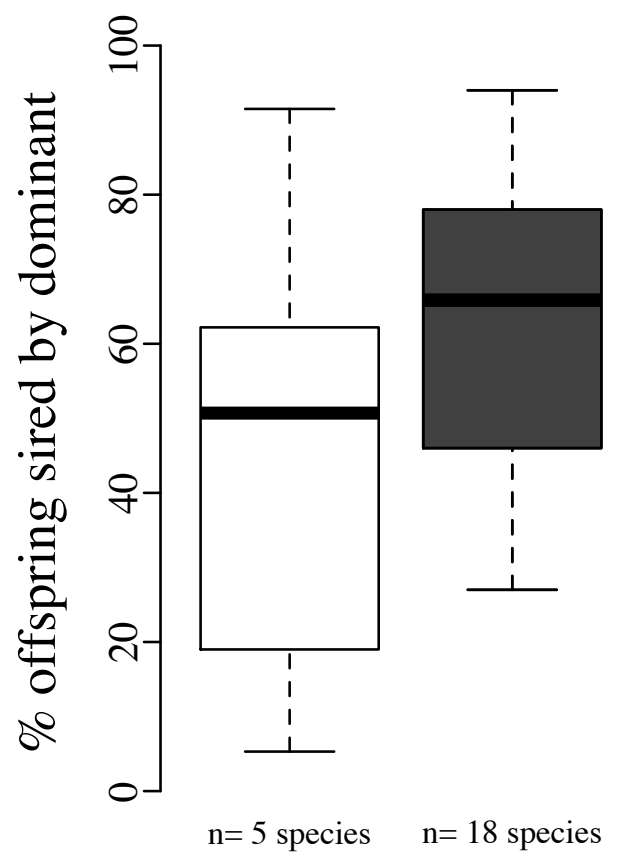

(c) Tenure length

No Infanticide Infanticide

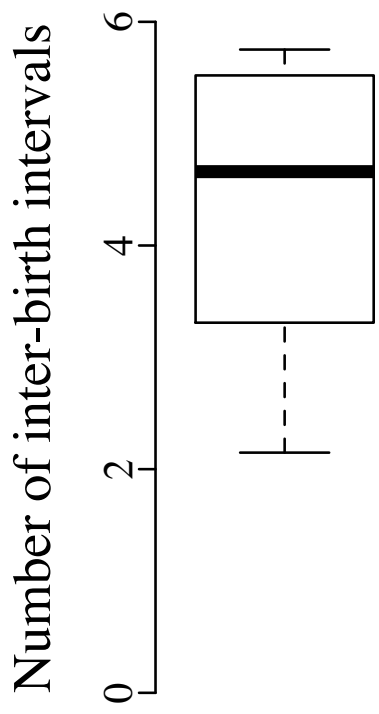

$\mathrm{n}=6$ species

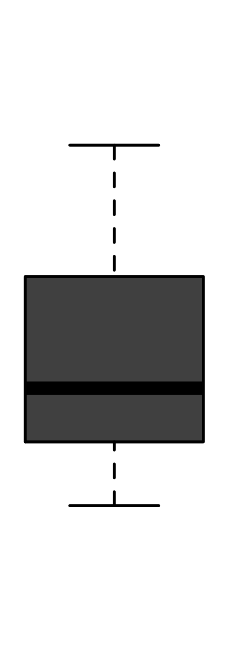

$\mathrm{n}=34$ species 
Figure 3

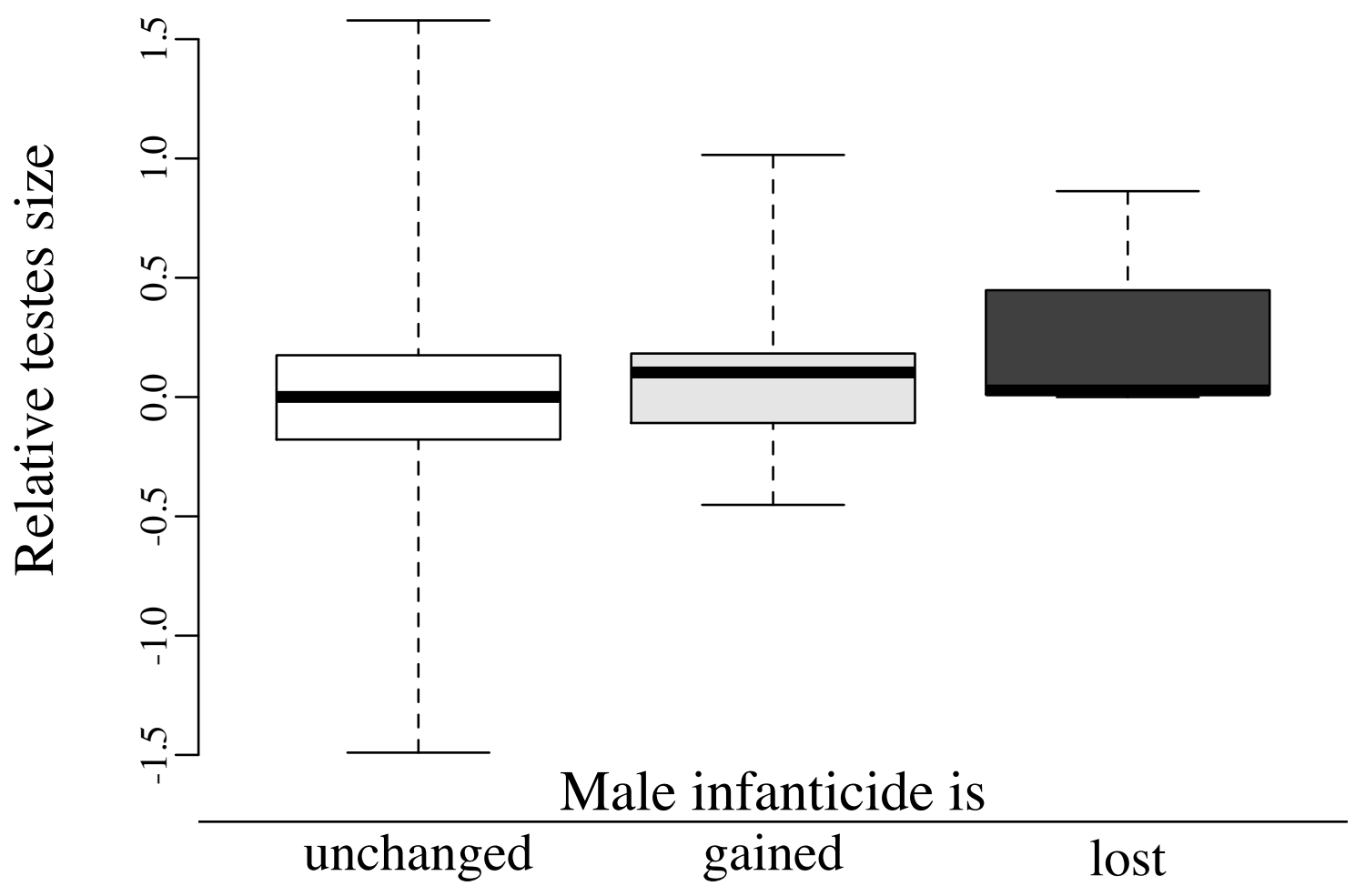




\title{
Supplementary Materials
}

\author{
for

\section{The evolution of infanticide by males in mammalian societies}

\author{
D. Lukas* \& E. Huchard \\ contact:d1384@cam.ac.uk
}

This file includes:

Data and Methods (pages 1-6)

Supporting results for multivariate and the Ornstein-Uhlenbeck models (pages 6-7)

Credit for animal drawings used in Figure 1 (page 9)

Supplementary Table 1: inferences from Bayestraits' Discrete (page 10)

Supplementary Table 2: results from analyses run across all mammals (page 11)

Supplementary Table 3: results from analyses run across primates (page 12)

Supplementary Table 4: data on distribution of male infanticide (pages 13-22)

\section{Data and Methods}

To determine the taxonomic distribution of male infanticide, we relied on its observed distribution, which is documented for an increasing number of species that have been the focus of detailed and prolonged field studies. We took care to include only species in which this behaviour could have been observed in natural populations because they had been studied continuously over more than 3 reproductive seasons, including observations of females with unweaned juveniles, in order to minimize the risk of introducing noise in the data if some species were misclassified as "male infanticide absent" (see Supplementary Table 4). For the opposite, we only included a species as "male infanticide present" if the 
data unambiguously showed that the individual committing infanticide was an adult male. From databases and reviews we extracted information on life-history (seasonal breeding, lactation and gestation length, inter-birth interval, longevity, body mass at birth, litter size [25-27] and postpartum oestrous [28]), on mating system (reproductive skew [22], length of dominance tenure in males [20], testis size as an index of multiple male mating by females [23,29-34]) and on sociality (social organization [9], group composition [20,35]). We classified the social organization of a species as solitary if breeding females tolerate the proximity of adult conspecifics only during the mating season; as monogamous if a single breeding female and a single breeding male share a territory, potentially including nonbreeding offspring; as female-only groups where stable groups of breeding females associate permanently and males only join for mating; and as stable mixed-sex groups if two or more breeding females associate permanently with one or more male (9). Seasonal breeding was defined as an interbirth interval comprised between 360 and 370 days, and we used data on intra-annual variability in temperature (36) to verify that yearly breeding thus defined is associated with ecological seasonality (yearly variance in temperature 38.7, compared to 27.5 for non-seasonal breeders; lambda $=0.92, \mathrm{t}=-0.1, \mathrm{p}<0.001$ ). We chose to exclude species reproducing always at the same season but less than once a year on average from the seasonally breeding species, as infanticide is likely to provide males with benefits in this context if a female resumes cycling one year earlier than she would if her infant was alive. We provide a full data file in text format at the Knowledge Network for Biocomplexity (https://knb.ecoinformatics.org).

We relied on the updated mammalian supertree (19) to reflect the phylogenetic relatedness between species. The tree was truncated to match our sample using functions of the package 'ape' (37) in the statistical software R (48). We resolved polytomies randomly for all analyses that require bifurcating trees, and repeated each analysis with three independent resolutions, which in all cases gave consistent results. Phylogenetic reconstruction of discrete traits were performed across trees with dated branch lengths, across ultrametric trees in which all tips have the same distance to the root and branch lengths are proportional to the number of descendants (39), and across trees in which all 
branch lengths were transformed to equal one.

We used different approaches and methods to assess our hypotheses according to the type of prediction and data. Initially, we compared values of currently living species in which male infanticide is present to those in which male infanticide is absent without taking phylogeny into account by using Wilcoxon-tests. When assessing whether the distribution of a trait differed between species that were grouped into discrete categories while taking phylogeny into account, we used phylogenetic Anova as implemented in the R-package 'geiger' (40; indicated as pAN in the manuscript). We tested whether the presence or absence of infanticide explains variation in quantitative traits using phylogenetic generalized least squares regressions as implemented in the R-package 'CAPER' (41; indicated in the manuscript by listing the lambda-, t-, and p-value of the model) and examined whether changes in the traits most likely co-occur on the same branches by calculating phylogenetic independent contrasts using functions of the R-package 'ape'. To examine whether variation in continuous traits explained the distribution of infanticide across species we ran regression models in the R-package 'MCMCglmm' (42) that corrected for phylogenetic relatedness (indicated as pMCMC in the manuscript), using a fixed prior (43). The significance of factors in explaining variation in the dependent trait was assessed by the p-values (43). In addition to their presentation in the main manuscript, we also list all statistical results in Supplementary Table 2.

Both the phylogenetic generalized least squares regression and the MCMCglmm method estimate the extent of the phylogenetic signal, and thereby can correct for phylogeny to the appropriate degree (including the possibility of no phylogenetic signal). There are two traits, longevity and litter size, for which Wilcoxon tests returned a significant difference between species with and without infanticide that were not supported in analyses that controlled for phylogeny. We discuss these in the supplementary results below. In addition, to control for the possibility that some effects identified across all mammals might differ from patterns occurring within particular lineages of mammals, we repeated all analyses including only the 90 primate species in our sample. The significance of all the correlations reported are the same using the main dataset and the restricted, 
primate-specific dataset (see Supplementary Table 3). However, when only including primate species, we do not have sufficient power to investigate the evolutionary sequence of changes in group sex ratio and testis size in relation to transitions towards presence or absence of male infanticide.

In order to decipher causal associations between two traits that could be coded as binary (absence versus presence) we compared inference models in Bayestraits Discrete $(44,45)$. In Discrete, we compared the evolution of male infanticide against the evolution of each type of social organization (solitary, socially monogamous, harem, multi-female multi-male group) in separate models. We first checked for each association whether models that assume a dependent evolution between male infanticide and a particular type of social organization were better supported compared to models that assume an independent evolution of the traits. If the inference suggested a dependent evolution, we ran further models to investigate the potential directionality of the association: first, we tested whether models in which transitions in social organization were constrained to occur at identical rate in both the presence and the absence of male infanticide were less supported (which would indicate that transitions in social organization might depend on the presence of male infanticide); second, we assessed whether models in which transitions in male infanticide were constrained to occur at equal rates independent of the social organization were less supported (which would indicate that the evolution of male infanticide depends on a particular type of social organization). We assessed significance between dependent and independent models by comparing the likelihood ratio statistic against a chi-squared distribution with four degrees of freedom (45); unconstrained models were considered to explain the data significantly better if the likelihood ratio statistic exceeded a chi-squared distribution with one degree of freedom.

To investigate causal relationships between male infanticide and continuous traits (testis size relative to body size and group sex ratio) we applied flexible OrnsteinUhlenbeck models of trait diversification (24). Ornstein-Uhlenbeck models assume that a trait is under stabilizing selection toward a single or multiple adaptive optima. Specifically, we predicted that models that assume that relative testis size and group sex ratio evolve 
towards different values in lineages in which male infanticide is present compared to absent are statistically better supported than models that assume that relative testis size and group sex ratio evolve independently of the presence or absence of male infanticide. We performed the Ornstein-Uhlenbeck model reconstructions using functions of the R-package 'OUwie' (46). We first reconstructed the evolution of male infanticide. Next, we assessed two possible ways in which the presence of male infanticide could influence either relative testis size or group sex ratios: first, the presence of infanticide could speed up or slow down the rate of change, but average values of testis size and sex ratio are about the same; second, while the rate of change is the same, the presence of male infanticide could be associated with a different peak value of testis size or sex ratio. Peak values, in comparison to averages, take into account the possibility that the value might only have been reached once male infanticide has been present for a sufficient amount of evolutionary time. Any association that shows that peak values of either testis size or group sex ratio differ between lineages in which male infanticide is either present or absent could however also be the consequence of the reversed directionality: male infanticide evolves in lineages in which either testis size or group sex ratio have already reached extreme values. To differentiate the direction of causality in such cases, we performed two further sets of analyses. First, we compared the estimated peak values to the observed average values for extant species which either do or do not show male infanticide. If infanticide evolves only when the value of a given trait is already high (or low) but does not subsequently influence the evolution of this trait, the average value is expected to be similar to the peak value, because infanticide evolves when the condition matches. If, in contrast, infanticide does influence the evolution of the trait, then the peak value should be more extreme than the average value observed in extant species, because these likely include a number of species where infanticide has only evolved recently and where the trait has not yet reached its peak value. Second, we checked whether directional selection favouring a different value of the trait had already started before infanticide evolved. For these analyses, we included the branches just before the nodes at which infanticide most likely first evolved, in lineages associated with the presence of male infanticide. If the presence of male infanticide leads to a shift in the peak 
value, the inclusion of these additional branches should decrease or obscure any signal. If, alternatively, male infanticide only evolves in those lineages characterized by an extreme trait value, the inclusion of these additional branches should increase the strength of the signal. We report the results below.

\section{Supplementary results}

\section{Inference of non-phylogenetic model differs from that of phylogenetic model}

For longevity and litter-size, Wilcoxon-tests of the raw species values indicate a difference between species in which male infanticide is present as compared to absent. This difference does not hold in analyses controlling for phylogenetic relatedness. While including phylogenetic information could have introduced a bias if longevity and litter-size where to evolve in a more complex way than approximated by the shared co-ancestry between species, this scenario is unlikely because these two life-history traits generally show a strong phylogenetic signal. Instead, it appears that the association between male infanticide and longevity/litter-size is indirect, mediated by another trait that is approximated by the phylogenetic component and better explains the variance in longevity/litter-size. The factor mediating the relationship between male infanticide and longevity/litter-size is most likely group-living, which has a significant phylogenetic signal. This interpretation is supported by non-phylogenetic multivariate analyses which show that the presence of male infanticide no longer predicts variation in longevity/litter-size across species when controlling for the social organization (see Supplementary Table 2).

\section{Analyses including only the primate species in our sample}

The significance of all the correlations we report is the same when including only primate species in the analyses (90 of the 260 species are primates; see Supplementary Table 3). However, we do not have sufficient power with the more limited sample of species to investigate the evolutionary sequence of change of group sex ratio and testis size 
in relation to transitions in male infanticide. Here, the AIC values of models assuming that species with male infanticide are associated with different values of group sex ratio and testis size compared to species in which infanticide is absent are within 1.5 of the AIC values of models assuming similar values. In addition, the multivariate analyses suggest that, in primates, annual breeding and postpartum oestrus is closely linked, and postpartum oestrus is a better predictor of male infanticide than is annual breeding.

\section{Results of the Ornstein-Uhlenbeck model inferences}

For both sex ratio and testis size, the presence of infanticide seems to be associated with different peak values, but not with different rates of evolution (in both cases, the likelihoods of these best supported models differ by $>3$ from the likelihoods of the next models assuming different peak values and different rates, and by $>5$ from the likelihood of the best supported models assuming equal peak values). These findings match the regression analyses comparing changes in the values of the traits. To disentangle causality, we compared peak values to average values among extant species and investigated whether changes in either sex ratio or testis size most likely originated before or after the transition towards male infanticide.

In contemporary species with male infanticide, the average group sex ratio is 1 male per 2.5 females, whereas it is 1 male per 1.3 females in species without infanticide; these values do not differ from peak values ( 1 male per 2.4 females in species with infanticide; 1 male per 1.6 females in species without infanticide). In addition, the strength of the association between male infanticide and group sex ratio increased when we included additional branches located immediately before the evolution of male infanticide, as shown by increases in the likelihoods of models supporting two different peak values, relative to models supporting similar peak values. The peak value of group sex-ratio changed to 1 male per 2.8 females in lineages with infanticide, and to 1 male per 1.2 females in lineages without infanticide.

In contemporary species with male infanticide, average relative testis size is 0.20 (indicative of relatively large testes for a given body size), whereas it is -0.02 in species 
without infanticide; the peak value for species with infanticide appears much higher (0.48), whereas it is identical to the average relative testis size $(-0.03)$ for species without infanticide, suggesting that the evolution of infanticide induces changes in testis size. In addition, the association between relative testis size and male infanticide disappeared when we included additional branches located immediately before transitions to male infanticide, confirming that changes in testis size follow, rather than precede, transitions to male infanticide: in this case the best supported model suggested that peak values for testis size were identical in lineages with or without infanticide.

These results suggest that a male-biased sex ratio is a cause for the evolution of infanticide, whereas testis size increases as a consequence of infanticide. 


\section{Credit for animal drawings used in Figure 1}

All drawings were downloaded from PhyloPic: http://phylopic.org

Picture information is listed as:

Common name listed in figure (taxon identifier for picture on PhyloPic): Author

Starting from top, clockwise:

Old World primate (Papio): Uncredited

Hare (Leporidae): Sarah Werning

Squirrel (Sciuridae): Catherine Yasuda

Marmot (Marmota monax): Michael Keesey

Mice (Muridae): Madeleine Price Ball

Marsupial (Marsupialia): Sarah Werning

Bat (Chiroptera): Michael Keesey

Mongoose (Herpestoidae): Michael Keesey

Felids (Panthera): Sarah Werning

Canids (Canidae): Michael Keesey

Bear (Ursus): Steven Traver

Seal \& sealions (Pinnipedia): Steven Traver

Marten (Meles): Uncredited

Ungulate (Cervus): Steven Traver

Lemur (Daubentonia): Uncredited

Great ape (Gorilla): Michael Keesey

New World primate (Cebus): Sarah Werning 


\section{Supplementary Table 1: Inferences from Bayestraits' Discrete models investigating correlated evolution between male infanticide and social}

\section{organization}

Phylogenetic reconstructions that consider the evolution of male infanticide and social organization suggest that transitions to male infanticide depend on a social system involving bisexual groups (harem or multimale-multifemale). While male infanticide appears to evolve independently from social monogamy (and vice versa), transitions to male infanticide appear significantly more likely in lineages with bisexual groups. Changes in social organization do however not appear to be a consequence of male infanticide, as transitions to group living are equally likely when male infanticide is present or absent. The higher support for a dependent model in the case of group-living species appears to derive from this trait being evolutionarily stable, with transitions to this state much higher than losses of this state (regardless of the presence of infanticide). The values of delta log-likelihood represent the difference between the likelihood of the model presented and the likelihood of the best supported model (in all cases dependent and unconstrained), and values in bold with stars indicate models that are significantly less supported compared to this baseline model (based on a chisquare test comparison correcting for the difference in the number of parameters of each model).

\section{Delta log-likelihood of a model assuming the evolution of both traits to be}

\section{independent unconstrained \\ dependent and}

social monogamy

versus solitary/gregarious/bisexual group

group-living

versus solitary/monogamous

multi-female multi-male group

versus solitary/monogamous/gregarious/harem

\section{harem}

versus solitary/monogamous/gregarious/multi-male
$7.7 * *$

13.1 **

$8.5 * *$
0

0

0

\section{social organization \\ to be equal whether infanticide}

occurs or not
0.5

in unconstrained dependent mode transition rate to groupliving from infanticide $<2$ times lowe

\section{2}

in unconstrained dependent mode transition rate to group living from infanticide $<2$ times lower

in unconstrained dependent model transition rate to harem from infanticide $<2$ times lower

\section{1}

in unconstrained dependent model transition rate to infanticide from groupliving $\sim 2$ times higher

\section{1 *}

in unconstrained dependent model transition rate to infanticide from group living $\sim 3$ times higher

\section{3 *}

in unconstrained dependent model transition rate to infanticide from group living $\sim 4$ times higher 


\section{Supplementary Table 2: Summary of the results of the statistical analyses including all species.}

The table presents for the non-phylogenetic Wilcoxon tests the test value $W$ and significance value $p$, for phylogenetic Anova (PhyloAnova) the significance value $p$, for phylogenetic generalized least squares regression (PGLS) the most likely value for the transformation of the branch lengths $l a m b d a$, whether this lambda value is significantly different from a value that reflects no phylogenetic signal $(p$ lambda $=0)$ or a value that reflects that change occurs consistently over evolutionary time ( $p$ lambda $=1)$, for the MCMCglmm regression model the significance value $p$, and for multivariate regression models in MCMCglmm the significance values $p$ for the two traits analysed simultaneously in one row.

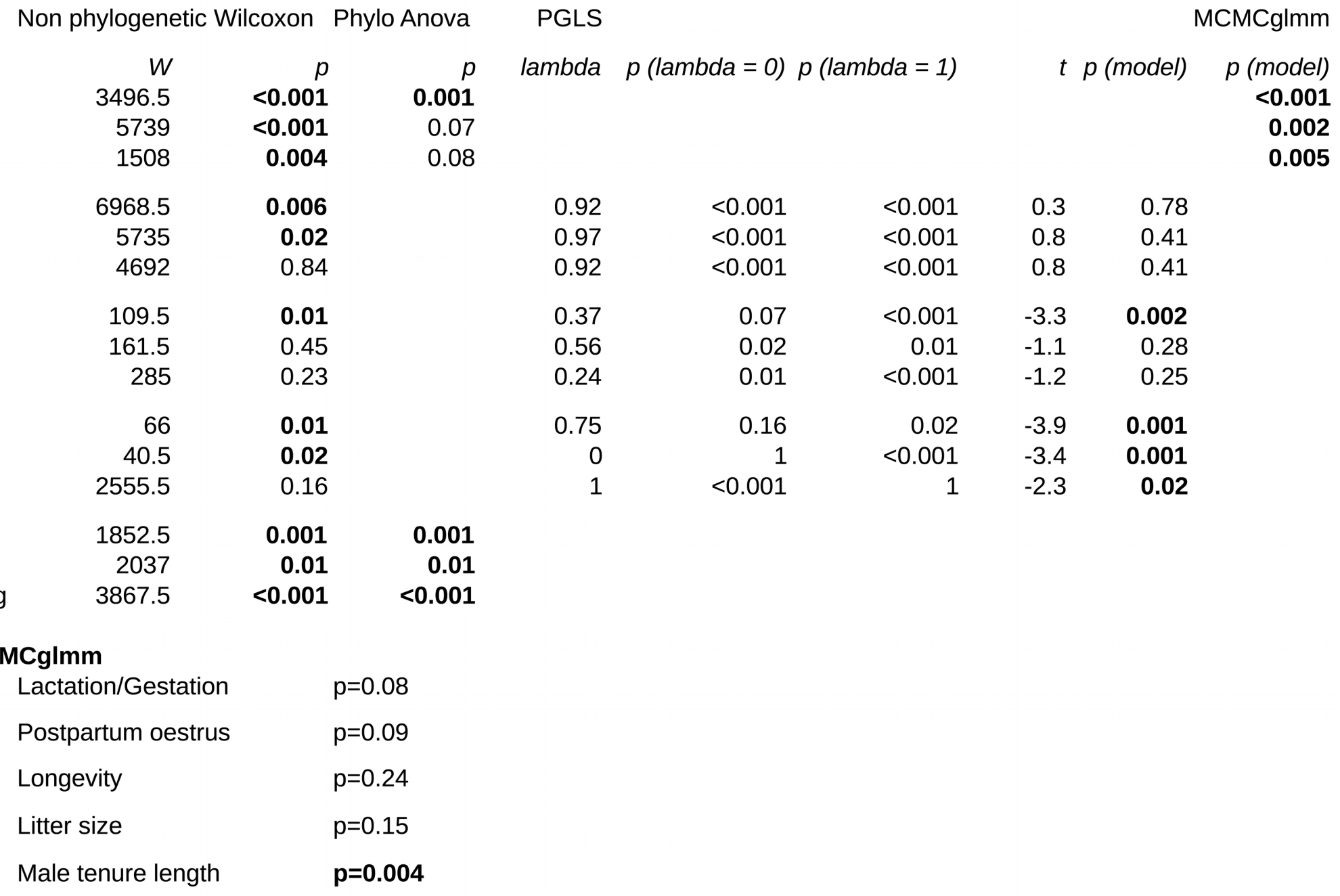




\section{Supplementary Table 3: Summary of the results of the statistical analyses including only primates.}

The table presents for the non-phylogenetic Wilcoxon tests the test value $W$ and significance value $p$, for phylogenetic Anova (PhyloAnova) the significance value $p$, for phylogenetic generalized least squares regression (PGLS) the most likely value for the transformation of the branch lengths $l a m b d a$, whether this lambda value is significantly different from a value that reflects no phylogenetic signal $(p$ lambda $=0)$ or a value that reflects that change occurs consistently over evolutionary time ( $p$ lambda $=1)$, for the MCMCglmm regression model the significance value $p$, and for multivariate regression models in MCMCglmm the significance values $p$ for the two traits analysed simultaneously in one row.

Non phylogenetic Wilcoxon Phylo Anova

Seasonality

Lactation/Gestation

Postpartum oestrus

Longevity

Litter size

Offspring weight

Sex ratio

Group size

Females per group

Reproductive skew

Tenure length

Testes size

Solitary vs Monogamous

Solitary vs Groupliving

Monogamous vs Groupliving

$\begin{array}{rrr}W & p & p \\ 316 & <0.001 & \mathbf{0 . 0 1} \\ 334.5 & <0.001 & \mathbf{0 . 0 4} \\ 42 & <\mathbf{0 . 0 0 1} & \mathbf{0 . 0 1} \\ 564 & 0.28 & \\ 410 & \mathbf{0 . 0 1} & \\ 246 & 0.23 & \\ 86.5 & <\mathbf{0 . 0 0 1} & \\ 69.5 & 0.2 & \\ 217.5 & 0.8 & \\ 25 & \mathbf{0 . 0 4} & \\ 40.5 & \mathbf{0 . 0 2} & \\ 203 & 0.44 & \\ 31.5 & 0.94 & 0.86 \\ 48 & \mathbf{0 . 0 0 6} & \mathbf{0 . 0 0 3} \\ 730.5 & <\mathbf{0 . 0 0 1} & \mathbf{0 . 0 0 1}\end{array}$

PGLS

lambda $p(l a m b d a=0) p(l a m b d a=1)$
MCMCglmm

t $p$ (model)

$p$ (model)

$<0.001$

0.003

$<0.001$

\section{Multivariate models in MCMCglmm}

Seasonality $\mathbf{p}=\mathbf{0 . 0 2} \quad$ Lactation/Gestation

Seasonality $p=0.12$

Postpartum oestrus

$p=0.001$ 


\section{References and notes}

1. R. A. Palombit, in The evolution of primate societies, J. C. Mitani, J. Call, P. Kappeler, R. A. Palombit, J. B. Silk, Eds. (Univ. Chicago Press, Chicago, 2012),

2. S. B. Hrdy, Male-male competition and infanticide among the langurs (Presbytis entellus) of Abu, Rajasthan. Folia Primatol. 22, 19-58 (1974).

3. S. B. Hrdy, Infanticide among animals: a review, classification, and examination of the implications for the reproductive strategies of females. Ethol. Sociobiol. 1, 1340 (1979).

4. L. A. Ebensperger, Strategies and counterstrategies to infanticide in mammals. Biol. Rev. 73, 321-346 (1998).

5. C. Janson, C. P. Van Schaik, in Infanticide by males and its implications, C. P. Van Schaik, C. Janson, Eds. (Cambridge Univ. Press, Cambridge, 2000), pp 469-494.

235 6. C. L. Nunn, C. P. Van Schaik, in Infanticide by Males and Its Implications, C. P. van Schaik, C. H. Janson, Eds. (Cambridge Univ. Press, Cambridge, 2000), pp. 388-412.

7. D. T. Blumstein, in Infanticide by Males and Its Implications, C. P. van Schaik, C. H. Janson, Eds. (Cambridge Univ. Press, Cambridge, 2000), pp. 178-197.

240 8. C. P. van Schaik, in Infanticide by Males and Its Implications, C. P. van Schaik, C. H. Janson, Eds. (Cambridge Univ. Press, Cambridge, 2000), pp. 61-71.

9. D. Lukas, T. H. Clutton-Brock, The evolution of social monogamy in mammals. Science 341, 526-530 (2013).

10. C. Opie, Q. D. Atkinson, R. I. M. Dunbar, S. Schultz, Male infanticide leads to social monogamy in mammals. Proc. Natl. Acad. Sci. U. S. A. 110, 13328-13332 (2013).

11. G. R. Pradhan, C. P. Van Schaik, Infanticide-driven intersexual conflict over matings in primates and its effects on social organization. Behaviour 145, 251-275 (2008).

250 12. J. A. Teichroeb, E. C. Wikberg, I. Badescu, L. J. Macdonald, P. Sicotte, Infanticide risk and male quality influence optimal group composition for Colobus vellerosus. Behav. Ecol. 23, 1348-1359 (2012).

13. C. P. van Schaik, E. P. Dunbar, The evolution of monogamy in large primates: a new hypothesis and some crucial tests. Behaviour 115, 30-62 (1990).

255 14. C. Borries, T. Savini, A. Koenig, Social monogamy and the threat of infanticide in larger mammals. Behav. Ecol. Sociobiol. 65, 685-693 (2011).

15. C. P. van Schaik, P. M. Kappeler, Infanticide risk and the evolution of male-female association in primates. Proc. R. Soc. B 264, 1687-1694 (1997).

16. M. A. van Noordwijk, C. P. van Schaik, in Infanticide by Males and Its Implications, C. P. Van Schaik, C. H. Janson, Eds. (Cambridge Univ. Press, Cambridge, 2000), pp. 322-360.

17. J. O. Wolff, D. W. Macdonald, Promiscuous females protect their offspring. Trends Ecol. Evol. 19, 127-134 (2004).

18. Material and Method is available on Science Online.

265 19. S. A. Fritz, O. R. Bininda-Emonds, A. Purvis, Geographical variation in predictors of mammalian extinction risk: big is bad, but only in the tropics. Ecol. Lett. 12, 538-549 (2009).

20. D. Lukas, T. Clutton-Brock, Costs of mating competition limit male lifetime breeding success in polygynous mammals. Proc. R. Soc. B 281, 20140418 (2014). 
270 21. C. M. Crockett, C. H. Janson, in Infanticide by males and its implications, C. P. Van Schaik, C. H. Janson, Eds. (Cambridge Univ. Press, Cambridge, 2000), pp. 75-98.

22. C. D. Soulsbury, Genetic patterns of paternity and testes size in mammals. PLOS One 5, e9581 (2010).

275 23. A. H. Harcourt, P. H. Harvey, S. G. Larson, R. V. Short, Testis weight, body weight and breeding system in primates. Nature 293, 55-57 (1981).

24. J. M. Beaulieu, D. C. Jhwueng, C. Boettiger, B. O’Meara, Modeling stabilizing selection: expanding the Ornstein-Uhlenbeck model of adaptive evolution. Evolution 66, 2369-2383 (2012).

280 25. S. K. M. Ernest, Life history characteristics of placental nonvolant mammals, Ecology 84, 3402-3402 (2003).

26. K. E. Jones et al., PanTHERIA: a species-level database of life history, ecology, and geography of extant and recently extinct mammals, Ecology 90, 2648-2648 (2009).

285 27. J. P. de Magalhães, J. Costa, A database of vertebrate longevity records and their relation to other life-history traits. J. Evol. Biol. 22, 1770-1774 (2009).

28. C. P. van Schaik. In: (ed. P. M. Kappeler) Primate males: causes and consequences of variation in group composition (Cambridge Univ. Press, Cambridge, 2000), pp 34-52.

290 29. G. J. Kenagy, S. C. Trombulak, Size and function of mammalian testes in relation to body size. J. Mammal. 67, 1-22 (1986).

30. K. E. Glander, P. C. Wright, P. S. Daniels, A. M. Merenlender, Morphometrics and testicle size of rain forest lemur species from southeastern Madagascar. J. Human Evol. 22, 1-17 (1992).

295 31. D. J. Hosken, Sperm competition in bats. Proc. Roy. Soc. B, 264, 385-392 (1997).

32. R. R. Stallmann, A. H. Harcourt, Size matters: the (negative) allometry of copulatory duration in mammals. Biol. J. Linnean Soc. 87, 185-193 (2006).

33. G. Iossa, C. D. Soulsbury, P. J. Baker, S. Harris, Sperm competition and the evolution of testes size in terrestrial mammalian carnivores. Funct. Ecol. 22, 655$300 \quad 662(2008)$.

34. T. J. Orr, M. Zuk, Does delayed fertilization facilitate sperm competition in bats? Behav. Ecol. Sociobiol. 67, 1903-1913 (2013).

35. L. M. Carnes, C. L. Nunn, R. J. Lewis, Effects of the distribution of female primates on the number of males. PLOS One 6, e19853 (2011).

305 36. C. A. Botero, R. Dor, C. M. McCain, R. J. Safran, Environmental harshness is positively correlated with intraspecific divergence in mammals and birds. Mol. Ecol. 23, 259-268 (2014).

37. E. Paradis, J. Claude, K. Strimmer, APE: analyses of phylogenetics and evolution in R language. Bioinf. 20, 289-290 (2004).

$310 \quad 38 . \quad$ R Development Core Team, $R$ : A Language and Environment for Statistical Computing. (R Foundation for Statistical Computing, Vienna, 2010).

39. A. Grafen, The phylogenetic regression. Phil. Trans. Roy. Soc. B 326, 119-157 (1989).

40. L. J. Harmon, J. T. Weir, C. D. Brock, R. E. Glor, W. Challenger, W. Geiger:

315 investigating evolutionary radiations. Bioinf. 24, 129-131 (2008).

41. C. D. L. Orme, R. P. Freckleton, G. H. Thomas, T. Petzoldt, S. A. Fritz, N. J. Isaac, N. J. B. caper: Comparative Analyses of Phylogenetics and Evolution in R, Methods Ecol. Evol. 3, 145-151 (2012).

42. J. D. Hadfield, S. Nakagawa, General quantitative genetic methods for 
comparative biology: phylogenies, taxonomies and multi-trait models for continuous and categorical characters, J. Evol. Biol. 23, 494-508 (2010).

43. J. Hadfield, MCMCglmm: Markov chain Monte Carlo methods for Generalised Linear Mixed Models. Retrieved from: cran.uvigo.es/web/packages/MCMCglmm/vignettes/Tutorial.pdf (2010).

44. M. Pagel, Inferring the historical patterns of biological evolution, Nature 401, 877-884 (1999).

45. M. Pagel, A. Meade, Bayesian analysis of correlated evolution of discrete characters by reversible-jump Markov chain Monte Carlo, Am. Nat. 167, 808-825 (2006).

330 46. J. M. Beaulieu, B. O'Meara, OUwie: Analysis of evolutionary rates in an OU framework. R package version 1.42. http://CRAN.R-project.org/package=OUwie (2014).

47. L. Hunter, J. D. Skinner, Do male cheetahs Acinonys jubatus commit infanticide? Trans. Roy. Soc. S. Africa 56, 79-82 (2003).

335 48. S. J. Ward, Life-history of the feathertail glider, Acrobates pygmaeus (Acrobatidae, Marsupialia) in South-Eastern Australia. Austr. J. Zool. 38, 503-517 (1990).

49. C. Averbeck, Doctoral dissertation, Technische Universität München (2002).

50. P. A. Fleming, \& Nicolson, S. W. Sex differences in space use, body condition and survivorship during the breeding season in the Namaqua rock mouse, Aethomys namaquensis. African Zool. 39, 123-132 (2004).

51. A. Glatston, in Conservation and management W. Andrew, Ed. (Noyes 2010), pp. 488.

52. B. E. Sæther et al., Offspring sex ratio in moose Alces alces in relation to paternal age: an experiment. Wildlife Biol. 10, 51-57 (2004).

53. M. Galetti, F. Pedroni, M. Paschoal, Infanticide in the brown howler monkey, Alouatta fusca. Neotrop. Primates 2, 6-7 (1994).

54. A. Treves, A. Drescher, C. T. Snowdon, Maternal watchfulness in black howler monkeys (Alouatta pigra). Ethology 109, 135-146 (2003).

350 55. S. van Belle, A. Kulp, R. Thiessen-Bock, M. Garcia, A. Estrada, Observed infanticides following a male immigration event in black howler monkeys, Alouatta pigra, at Palenque National Park, Mexico. Primates 51, 279-284 (2010).

56. C. E. Holleley, C. R. Dickman, M. S. Crowther, B. P. Oldroyd, Size breeds success: multiple paternity, multivariate selection and male semelparity in a small marsupial, Antechinus stuartii. Mol. Ecol. 15, 3439-3448 (2006).

57. C. N. Jacques, J. A. Jenks, Antipredatory defense of neonatal pronghorm (Antilocapra americana) by yearling male pronghorn in Southwestern South Dakota. West. North Amer. Nat. 70, 570-572 (2010).

58. S. J. Dunn, E. Clancey, L. P. Waits, J. A. Byers, Inbreeding depression in 360 pronghorn (Antilocapra americana) fawns. Mol. Ecol. 20, 4889-4898 (2011).

59. T. J. O'Shea, T. A. Vaughan, Nocturnal and seasonal activities of the pallid bat, Antrozous pallidus. J. Mammal. 58, 269-284 (1977).

60. M. Huck, M. Rotundo, E. Fernandez-Duque, Growth and development in wild owl monkeys (Aotus azarai) of Argentina. Int. J. Primatol. 32, 1133-1152 (2011).

365 61. M. Huck, E. Fernandez-Duque, Children of divorce: effects of adult replacements on previous offspring in Argentinean owl monkeys. Behav. Ecol. Sociobiol. 66, 505-517 (2012). 
62. C. J. A. Bradshaw, R. J. Barker, R. G. Harcourt, L. S. Davis, Estimating survival and capture probability of fur seal pups using multistate mark-recapture models. $J$. Mammal. 84, 65-80 (2003).

63. F. Trillmich, Maternal investment and sex-allocation in the Galapagos fur seal, Arctocephalus galapagoensis. Behav. Ecol. Sociobiol. 19, 157-164 (1986).

64. D. W. Doidge, J. P. Croxhall, J. R. Baker, Density-dependent pup mortality in the Antarctic fur seal Arctocephalus gazella at South Georgia. J. Zool. 202, 449-460 (1984).

65. R. Harcourt, Factors affecting early mortality in the South American fur seal Arctocephalus gazella at South Georgia. J. Zool. 226, 259-270 (1992).

66. J. Gibbens, J. P. Y. Arnould, Age-specific growth, survival, and population dynamics of female Australian fur seals. Can. J. Zool. 87, 902-911 (2009).

380 67. G. Beauplet, C. Barbraud, M. Chambellant, C. Guinet, Interannual variation in the post-weaning and juvenile survival of subantarctic fur seals: influence of pup sex, growth rate and oceanographic conditions. J. Anim. Ecol. 74, 1160-1172 (2005).

68. K. N. Gibson et al., Intra-community infanticide and forced copulation in spider monkeys: a multi-site comparison between Cocha Cashu, Peru and Punta Laguna, Mexico. Am. J. Primatol. 70, 485-489 (2008).

69. K. Y. Slater, C. M. Schaffner, F. Aureli, Sex differences in the social behavior of wild spider monkeys (Ateles geoffroyi yucatanensis). Am. J. Primatol. 71, 21-29 (2009).

70. M. McFarland Symington, Sex ratio and maternal rank in wild spider monkeys: when daughters disperse. Behav. Ecol. Sociobiol. 20, 421-425 (1987).

71. M. M. Symington, Demography, ranging patterns, and activity budgets of black spider monkeys (Ateles paniscus chamek) in the Manu National Park, Peru. Am. J. Primatol. 15, 45-67 (1988).

72. A. Fuentes, Patterns and trends in primate pair bonds. Int. J. Primatol. 23, 953-978

73. D. F. Lott, American bison socioecology. Appl. Anim. Behav. Science 29, 135-145 (1991).

74. K. Daleszczyk, Mother-calf relationships and maternal investment in European bison Bison bonasus. Acta Theriologica 49, 555-566 (2004).

$400 \quad 75 . \quad$ K. B. Strier, Faces in the forest: the endangered muriqui monkeys of Brazil. (Oxford Univ. Press, Oxford, 1992).

76. K. B. Strier, S. L. Mendes, in Long-term field studies of primates. P. M. Kappeler, D. P. Watts, Eds. (2012), pp. 125-140.

77. J. R. B. Alfred, J. P. Sati, On the first record of infanticide in the hoolock gibbon

78. A. Kumar, A. Devi, A. K. Gupta, K. Sarma, in Rare animals of India, Singaravelan, Ed. (Bentham Science Publisher, 2013), pp. 242-266.

79. L. M. Porter, Social organization, reproduction and rearing strategies of Callimico goeldii: New clues from the wild. Folia Primatol. 72, 69-79 (2001).

410 80. R. Hilario, S. F. Ferrari, Double infanticide in a free-ranging group of buffyheaded marmosets, Callithrix flaviceps. J. Ethol. 28, 195-199 (2010).

81. L. J. Digby, Infant care, infanticide, and female reproductive strategies in polygynous groups of common marmosets (Callithrix jacchus). Behav. Ecol. Sociobiol. 37, 51-61 (1995).

415 82. L. K. Corbett, Social dynamics of a captive dingo pack: population regulation by dominant female infanticide. Ethology 78, 177-198 (1988).

83. P. McLeod, Infanticide by female wolves. Can. J. Zool. 68, 402-404 (1990). 
84. N. Jenner, PhD thesis, Zoological Society of London's Institute of Zoology, London and University of Kent, Canterbury, UK (2008).

420 85. C. SilleroZubiri, D. Gottelli, D. W. Macdonald, Male philopatry, extra pack copulations and inbreeding avoidance in Ethiopian wolves (Canis simensis). Behav. Ecol. Sociobiol. 38, 331-340 (1996).

86. R. Andersen, J. D. Linnell, Ecological correlates of mortality of roe deer fawns in a predator-free environment. Can. J. Zool. 76, 1217-1225 (1998).

425 87. M. B. Hennessy, K. L. Bullinger, G. Neisen, S. Kaiser, N. Sachser, Social organization predicts nature of infant-adult interactions in two species of wild guinea pigs (Cavia aperea and Galea monasteriensis). J. Comp. Psychol. 120, 12-18 (2006).

88. C. Kraus, F. Trillmich, J. Kunkele, Reproduction and growth in a precocial small mammal, Cavia magna. J. Mammal. 86, 763-772 (2005).

89. N. Sachser, Of domestic and wild guinea pigs: studies in sociophysiology, domestication, and social evolution. Naturwissenschaften 85, 307-317 (1998).

90. C. Janson, M. C. Baldovino, M. Di Bitetti, in Long-Term Field Studies of Primates, P. M. Kappeler, W. D. P., Eds. (Springer-Verlag, Berlin, 2012), pp. 185212.

91. J. H. Manson, J. Gros-Louis, S. Perry, Three apparent cases of infanticide by males in wild white-faced capuchins (Cebus capucinus). Folia Primatol. 75, 104-106 (2004).

92. P. Ramírez-Llorens, M. S. Di Bitetti, M. C. Baldovino, C. H. Janson, Infanticide in black capuchin monkeys (Cebus apella nigritus) in Iguazu National Park, Argentina. Am. J. Primatol. 70, 473-484 (2008).

93. F. Range, R. Noë, Familiarity and dominance relations among female sooty mangabeys in the Taï National Park. Am. J. Primatol. 56, 137-153 (2002).

94. F. Range, Social behavior of free-ranging juvenile sooty mangabeys (Cercocebus torquatus atys). Behav. Ecol. Sociobiol. 59, 511-520 (2006).

95. S. P. Henzi, M. Lawes, Breeding season influxes and the behaviour of adult male samango monkeys (Cercopithecus mitis albogularis). Folia Primatol. 48, 125-136 (1987).

96. F. Bourlière, C. Hunkeler, M. Bertrand, in Old World Monkeys: Evolution, Systematics and Behavior, J. R. Napier, P. H. Napier, Eds. (Academic Press, New York, 1970).

97. F. E. Guinness, T. H. Clutton-Brock, S. D. Albon, Factors affecting calf mortality in red deer (Cervus elaphus). J. Anim. Ecol. 47, 817-832 (1978).

98. J. M. Dixon, L. Huxley, Observations on a maternity colony of Gould's wattled bat Chalinolobus gouldii (Chiroptera: Vespertilionidae). Mammalia 53, 395-414 (1989).

99. J. Fietz et al., High rates of extra-pair young in the pair-living fat-tailed dwarf lemur, Cheirogaleus medius. Behav. Ecol. Sociobiol. 49, 8-17 (2000).

100. J. Fietz, K. H. Dausmann, Costs and potential benefits of parental care in the nocturnal fat-tailed dwarf lemur (Cheirogaleus medius). Folia Primatol. 74, 246-258 (2003).

101. A. Treves, Primate social systems: conspecific threat and coercion-defense hypotheses. Folia Primatol. 69, 81-88 (1998).

102. J. A. Horrocks, Life-history chracteristics of a wild population of vervet monkeys (Cercopithecus aethiops) in Barbados, West Indies. Int. J. Primatol. 7, 31-47 (1986). 
103. L. A. Isbell, T. P. Young, K. E. Jaffe, A. A. Carlson, R. L. Chancellor, Demography and life histories of sympatric patas monkeys, Erythrocebus patas, and vervets, Cercopithecus aethiops, in Laikipia, Kenya. Int. J. Primatol. 30, 103-124 (2009).

104. R. D. Estes, R. K. Estes, The birth and survival of wildebeest calves. Zeitschrift für Tierpsychologie 50, 45-95 (1979).

105. D. Cantoni, P. Vogel, Social organization and mating system of free-ranging, greater white-toothed shrews, Crocidura russula. Anim. Behav. 38, 205-214 (1989).

106. H. Hofer, M. L. East, in Serengeti II. Dynamics, Management and Conservation of an Ecosystem, A. R. E. Sinclair, P. Arcese, Eds. (University Press, Chicago, 1995), pp. 332-363.

107. A. J. T. Johnsingh, Reproductive and social behavior of the Dhole, Cuon Alpinus (Canidae). J. Zool. 198, 443-463 (1982).

480 108. T. N. C. Vidya, Z. Balmforth, A. Le Roux, M. I. Cherry, Genetic structure, relatedness and helping behaviour in the yellow mongoose in a farmland and a natural habitat. J. Zool. 278, 57-64 (2009).

109. J. L. Hoogland, Aggression, ectoparasitism, and other possible costs of prairie dog (Sciuridae, Cynomys spp.) coloniality. Behaviour 69, 1-35 (1979).

110. L. A. Ebensperger, D. T. Blumstein, in Rodent societies: an ecological and evolutionary perspective, J. O. Wolff, P. W. Sherman, Eds. (The University of Chicago Press, Chicago, 2007), pp. 267-279.

111. T. H. Kunz, L. A. Ebensperger, Why does infanticide seem so rare in bats? Acta Chiropterologica 1, 17-29 (1999).

490 112. C. Lydersen, K. M. Kovacs, M. O. Hammill, Energetics during nursing and early postweaning fasting in hooded seal (Cystophora cristata) pups from the Gulf of St Lawrence, Canada. J. Comp. Physiol. B 167, 81-88 (1997).

113. K. Kraaijeveld, F. J. Kraaijeveld-Smit, G. J. Adcock, Does female mortality drive male semelparity in dasyurid marsupials? Proc. R. Soc. B 270, S251-S253 (2003).

114. R. B. Weladji, K. Laflamme-Mayer, Influence of environmental conditions on sex allocation in the black rhinoceros population of Mkhuze Game Reserve, South Africa. Afr. J. Ecol. 49, 471-480 (2011).

115. D. D. Hopkins, R. B. Forbes, Dietary patterns of the Virginia opossum in an urban environment. The Murrelet 61, 20-30 (1980).

500 116. A. B. Taber, D. W. Macdonald, Communal breeding in the mara, Dolichotis patagonum. J. Zool. 227, 439-452 (1992).

117. M. Riedman, J. A. Estes, The sea otter (Enhydra lutris): behavior, ecology, and natural history. Biological report 90, 1-126 (1990).

118. R. J. Kilgour, \& Brigham, R. M., The relationships between behavioural categories and social Influences in the gregarious big brown bat (Eptesicus fuscus). Ethology 119, 189-198 (2013).

119. R. K. Smith, A. Marais, P. Chadwick, P. H. Lloyd, R. A. Hill, Monitoring and management of the endangered Cape mountain zebra Equus zebra zebra in the Western Cape, South Africa. Afr. J. Ecol. 46, 207-213 (2008).

$510 \quad 120 . \quad$ P. H. Lloyd, O. A. E. Rasa, Status, reproductive success and fitness in Cape mountain zebra (Equus zebra zebra). Behav. Ecol. Sociobiol. 25, 411-420 (1989).

121. K. L. Enstam, L. A. Isbell, T. W. De Maar, Male demography, female mating behavior and infanticide in wild patas monkeys. Int. J. Primatol. 23, 85-104 (2002).

122. F. C. Cerqueira Santos, J. Rodriges, A. A. Correa, K. R. Groch, Behaviour of pairs of female \& young of Eubalaena australis (Desmoulins, 1822) in the reproductive 
period of 2008, Ribanceira and Ibiraquera, Santa Catarina, Brazil. Ensaios e Ciencia 14, 83-101 (2010).

123. A. Jolly et al., Infant killing, wounding and predation in Eulemur and Lemur. Int. J. Primatol. 21, 21-40 (1999).

520 124. J. Andrews, Infanticide by a female black lemur, Eulemur macaco, in disturbed habitat on Nosy Be, North-Western Madagascar. Folia Primatol. 69, 14-17 (1998).

125. F. Bruemmer, Rough rookeries. Natural History 103, 26-32 (1994).

126. D. Pontier, E. Natoli, Infanticide in rural male cats (Felis catus L.) as a reproductive mating tactic. Aggressive Behav. 25, 445-449 (1999).

525 127. O. Adrian, I. Brockmann, C. Hohoff, N. Sachser, Paternal behaviour in wild guinea pigs: a comparative study in three closely related species with different social and mating systems. J. Zool. 265, 97-105 (2005).

128. D. Baharav, Reproductive strategies in female mountain and dorcas gazelles ( $\mathrm{Ga}$ zella gazella gazella and Gazella dorcas). J. Zool. 200, 445-453 (1983).

530 129. K. D. Carter, J. M. Seddon, C. H. Frere, J. K. Carter, A. W. Goldizen, Fission-fusion dynamics in wild giraffes may be driven by kinship, spatial overlap and individual social preferences. Anim. Behav. 85, 385-394 (2012).

130. F. B. Bercovitch, P. S. M. Berry, Age proximity influences herd composition in wild giraffes. J. Zool. 290, 281-286 (2013).

535 131. E. J. Stokes, R. J. Parnell, C. Olejniczak, Female dispersal and reproductive success in wild western lowland gorillas (Gorilla gorilla gorilla). Behav. Ecol. Sociobiol. 54, 329-339 (2003).

132. S. S. Anderson, J. R. Baker, J. H. Prime, A. Baird, Mortality in grey seal pups: incidence and causes. J. Zool. 189, 407-417 (1979).

540 133. C. M. Nievergelt, T. Mutschler, A. T. Feistner, D. S. Woodruff, Social system of the Alaotran gentle lemur (Hapalemur griseus alaotrensis): genetic characterization of group composition and mating system. Am. J. Primatol. 57, 157-176 (2002).

134. S. R. Creel, P. M. Wasser, Failures of reproductive suppression in dwarf mongooses (Helogale parvula): accident or adaptation? Behav. Ecol. 2, 7-15 (1991).

135. O. A. E. Rasa, in Infanticide and Parental Care, S. Parmigiani, F. Vom Saal, Eds. (Harwood, Chur (Switzerland), 1984), pp. 301-320.

136. J. P. Rood, Male associations in a solitary mongoose. Anim. Behav. 39, 566 (1989).

137. P. M. Waser, B. Keane, S. R. Creel, L. F. Elliott, D. J. Minchella, Possible male coalitions in a solitary mongoose. Anim. Behav. 47, 289-294 (1994).

138. C. G. Faulkes, in Cooperative Breeding in Mammals, N. G. Solomon, J. A. French, Eds. (Cambridge University press, New York, 1997).

139. E. L. Karstad, R. J. Hudson, Social organization and communication of riverine hippopotami in southwestern Kenya. Mammalia 50, 153-164 (1986).

555 140. R. C. Beudels, S. M. Durant, J. Harwood, Assessing the risks of extinction for local populations of roan antelope Hippotragus equinus. Biol. Cons. 61, 107-116 (1992).

141. D. D. Owens, M. J. Owens, Helping behaviour in brown hyenas. Nature 308, 843845 (1984).

560 142. A. P. Wagner, S. Creel, L. G. Frank, S. T. Kalinowski, Patterns of relatedness and parentage in an asocial, polyandrous striped hyena population. Mol. Ecol. 16, 4356-4369 (2007).

143. A. P. Wagner, L. G. Frank, S. Creel, Spatial grouping in behaviourally solitary striped hyaenas, Hyaena hyaena. Anim. Behav. 75, 1131-1142 (2008). 
144. P. R. Stevenson, Activity and ranging patterns of Colombian woolly monkeys in north-western Amazonia. Primates 47, 239-247 (2006).

145. A. Di Fiore, A. Link, P. R. Stevenson, Scent marking in two western Amazonian populations of woolly monkeys (Lagothrix lagotricha). Am. J. Primatol. 68, 637649 (2006).

570 146. M. L. Sauther, R. W. Sussman, L. Gould, The socioecology of the ringtailed lemur: thirty-five years of research. Evol. Anthropol. 8, 120-132 (1999).

147. L. J. Digby, W. Saltzman, in The smallest anthropoids: the Marmoset/Callimico radiation, S. M. Ford, L. M. Porter, L. Davis, Eds. (Springer, New York, 2009), pp. 135-153.

575 148. S. Rasoloharijaona, B. Rakotosamimananana, E. Zimmerman, Infanticide by a male Milne-Edward's sportive lemur, Lepilemur edwardsi, in Ampijoroa, NWMadagascar. Int. J. Primatol. 21, 41-45 (2000).

149. K. M. Proffitt, J. J. Rotella, R. A. Garrott, Effects of pup age, maternal age, and birth date on pre-weaning survival rates of Weddell seals in Erebus Bay, Antarctica. Oikos 119, 1255-1264 (2010).

150. C. J. Krebs, R. Boonstra, S. Boutin, A. R. Sinclair, What drives the 10-year cycle of snowshoe hares? BioScience 51, 25-35 (2001).

151. M. E. Arlet et al., Correlations between social context and fecal glucocorticoid metabolite concentrations in free-ranging female gray-cheeked mangabeys (Lophocebus albigena) in Kibale National Park, Uganda. Folia Biol. 61, 3-4 (2013).

152. M. Knörnschild, K. Uebereschaer, M. Helbig, E. K. V. Kalko, Sexually selected infanticide in a polygynous bat. PLOS One 6, e25001 (2011).

153. K. A. I. Nekaris, Observations of mating, birthing and parental behaviour in three subspecies of slender loris (Loris tardigradus and Loris lydekkerianus) in India and Sri Lanka. Folia Primatol. 74, 312-336 (2003).

154. S. Radhakrishna, M. Singh, Infant development in the slender loris (Loris lydekkerianus lydekkerianus). Curr. Science 86, 1121-1127 (2004).

155. K. A. I. Nekaris, Social lives of adult mysore slender lorises (Loris lydekkerianus lydekkerianus). Am. J. Primatol. 68, 1171-1182 (2006).

595 156. C. J. Moss, The demography of an African elephant (Loxondota africana) population in Amboseli, Kenya. J. Zool. 255, 145-156 (2001).

157. G. Wittmeyer, W. M. Getz, Hierarchical dominance structure and social organization in African elephants, Loxodonta africana. Anim. Behav. 73, 671-681 (2007).

158. H. van Lawick, Solo: the story of an African wild dog. (Houghton Mifflin Company, Boston, MA., 1974).

159. G. Lopez, M. Lopez-Parra, L. Frenandez, J. M. Gil-Sanchez, M. A. Simon, First evidence of non-parental male infanticide in the endangered Iberian lynx (Lynx pardinus). Wildlife Biol. in Practice 6, 67-74 (2010).

160. G. Solanski, S. Zothansiama, Infanticide in captive stump-tailed macaques (Macaca arctoides) is in accordance with the sexual selection hypothesis. Curr. Science 104, 1081-1083 (2013).

161. D. Maestripieri, K. A. Carroll, Risk factors for infant abuse and neglect in groupliving rhesus monkeys. Psychol. Sci. 9, 143-145 (1998).

162. W. P. J. Dittus, Group fission among wild toque macaques as a consequence of female competition and environmental stress. Anim. Behav. 36, 1628-1645 (1988).

163. C. Berman, J. Li, H. Ogawa, C. Ionica, H. Yin, Primate tourism, range restriction, and infant risk among Macaca thibetana at Mt. Huangshan, China. Int. J. Primatol. 28, 1123-1141 (2007). 
164. Y. Muroyama, B. Thierry, Fatal attack on an infant by an adult female Tonkean macaque. Int. J. Primatol. 17, 219-227 (1996).

165. C. D. Nave, Doctoral dissertation, The University of Melbourne (2002).

166. P. N. M. Brotherton, M. B. Manser, Female dispersion and the evolution of monogamy in the dik-dik. Anim. Behav. 54, 1413-1424 (1997).

167. J. M. Setchell, E. J. Wickings, L. A. Knapp, Life history in male mandrills (Mandrillus sphinx): physical development, dominance rank, and group association. Am. J. Phys. Anthropol. 131, 498-510 (2006).

168. C. R. Maher, M. Duron, Mating system and paternity in woodchucks (Marmota monax). J. Mammal. 91, 628-635 (2010).

169. J. Erb, P. Coy, B. Sampson, Reproductive ecology of fisher and marten in Minnesota Minnesota Department of Natural Resources Summaries of Wildlife Research Findings 2009, 12-23 (2010).

170. J. Erb, B. Sampson, P. Coy, Survival and causes of mortality for fisher and marten in Minnesota. Minnesota Department of Natural Resources Summaries of Wildlife Research Findings 2009, 24-31 (2010).

630 171. C. M. Begg, K. S. Begg, J. T. Toit, M. G. L. Mills, Spatial organization of the honey badger Mellivora capensis in the southern Kalahari: homerange size and movement patterns. J. Zool. 265, 23-35 (2005).

172. A. B. Sargeant, R. J. Greenwood, J. L. Piehl, W. B. Bicknell, Recurrence, mortality, and dispersal of prairie striped skunks, Mephitis mephitis, and implications to rabies epizootiology. Can. Field Nat. 96, 312-316 (1982).

173. M. Eberle, P. M. Kappeler, Selected polyandry: female choice and intersexual conflict in a small nocturnal solitary primate (Microcebus murinus). Behav. Ecol. Sociobiol. 57, 91-100 (2004)

174. M. Eberle, P. M. Kappeler, Family insurance: kin selection and cooperative breeding in a solitary primate (Microcebus murinus). Behav. Ecol. Sociobiol. 60, 582588 (2006).

175. S. Heise, J. Lippke, Role of female aggression in prevention of infanticidal behavior in male common voles, Microtus arvalis (Pallas, 1779). Aggressive Behav. 23, 293-290 (1997).

645 176. B. J. LeBoeuf, K. T. Briggs, The cost of living in a seal harem. Mammalia 41, 167195 (1977).

177. B. J. LeBoeuf, R. J. Whiting, R. F. Gantt, Perinatal behavior of northern elephant seal females and their young. Behaviour 43, 121-156 (1972).

178. T. S. McCann, Aggressive and maternal activities of female southern elephant seals (Mirounga leonina). Anim. Behav. 30, 268-276 (1982).

179. D. J. Bonness, Fostering behavior in Hawaian monk seals: is there a reproductive cost? Behav. Ecol. Sociobiol. 27, 113-122 (1990).

180. L. M. Hiruki, W. G. Gilmartin, B. L. Becker, I. Stirling, Wounding in Hawaïan monk seals (Monachus schauinslandi). Can. J. Zoolog. 71, 458-468 (1993).

181. J. S. Gilchrist, Female eviction, abortion and infanticide in banded mongooses (Mungos mungo): implications for social control of reproduction and synchronized parturition. Behav. Ecol. 11, 1-6 (2006).

182. P. Hellstedt, H. Henttonen, Home range, habitat choice and activity of stoats (Mustela erminea) in a subarctic area. J. Zool. 269, 205-212 (2006).

660 183. D. Łupicki, J. Cichocki, R. Szkudlarek, A. Ważna, Cannibalism in maternity colonies of the greater mouse-eared bat Myotis myotis. Mammalia 74, 339 (2010).

184. T. Murai et al., Female transfer between one-male groups of proboscis monkey (Nasalis larvatus). Primates 48, 117-121 (2007). 
185. L. V. Higgins, R. A. Tedman, Attacks on pups by male Australian sea lions, Neophoca cinerea, and the effect on pup mortality. Mar. Mammal Sci. 71, 617-619 (1990).

186. M. G. Topping, J. S. Millar, Mating patterns and reproductive success in the bushy-tailed woodrat (Neotoma cinerea), as revealed by DNA fingerprinting. Behav. Ecol. Sociobiol. 43, 115-124 (1998).

670 187. P. C. Escherich, Social structure in bushy-tailed wood rat, Neotoma cinerea. Am. Zool. 15, 821-821 (1975).

188. P. Garcia-Diaz, M. Lizana, Field observation of male infanticide in the American mink (Neovison vison). North-Western J. Zool. 9, 438-440 (2013).

189. F. Drygala et al., Spatial organisation and intra-specific relationship of the raccoon dog Nyctereutes procyonoides in Central Europe. Wild. Biol. 14, 457-466 (2008).

190. F. Drygala, H. Zoller, N. Stier, H. Mix, M. Roth, Ranging and parental care of the raccoon dog Nyctereutes procyonoides during pup rearing. Acta Theriol. 53, 111119 (2008).

191. R. Kowalczyk, A. Zalewski, B. Jedrzejewska, H. Ansorge, A. N. Bunevich, Reproduction and mortality of invasive raccoon dogs (Nyctereutes procyonoides) in the Bialowieza Primeval Forest (eastern Poland). Ann. Zool. Fenn. 46, 291-301 (2009).

192. F. S. Dobson, A. T. Smith, W. X. Gao, Social and ecological influences on dispersal and philopatry in the plateau pika (Ochotona curzoniae). Behav. Ecol. 9, 622635 (1998).

193. L. A. Ebensperger, No infanticide in the hystricognath rodent, Octodon degus: does ecology play a role? Acta Ethol. 3, 89-93 (2001).

194. B. J. Le Boeuf, C. Campagna, in Infanticide and parental care, S. Parmigiani, F. vom Saal, Eds. (Harwood Academic Publishers, 1994), pp. 257-276.

690 195. M. G. Sams, R. L. Lochmiller, C. W. Qualls Jr, D. M. Leslie Jr, M. E. Payton, Physiological correlates of neonatal mortality in an overpopulated herd of whitetailed deer. J. Mammal. 77, 179-190 (1996).

196. B. E. Horner, J. M. Taylor, Growth and reproductive behavior in the southern grasshopper mouse. J. Mammal. 49, 644-660 (1968).

695 197. J. M. Gaillard, M. Festa-Bianchet, N. G. Yoccoz, A. Loison, C. Toigo, Temporal variation in fitness components and population dynamics of large herbivores. Ann. Rev. Ecol. Syst. 31, 367-393 (2000).

198. J. Künkele, Infanticide in wild rabbits (Oryctolagus cuniculus). J. Mammal. 73, 317-320 (1992).

700 199. L. E. Harding, Abu-Eid, O. F., Hamidan, N., \& al Sha lan, A. (2007). Reintroduction of the Arabian oryx Oryx leucoryx in Jordan: war and redemption. Oryx 41, 478 (2007).

200. C. Campagna, B. J. LeBoeuf, H. Cappozzo, Pup abduction and infanticide in southern sea lions. Behaviour 107, 44-60 (1988).

705 201. J. R. Malcolm, Socio-ecology of bat-eared foxes (Otocyon megalotis). J. Zool. 208, 457-467 (1986).

202. P. C. Lent, Ovibos moschatus. Mammal. Species 302, 1-9 (1988).

203. M. Festabianchet, J. T. Jorgenson, W. D. Wishart, Early weaning in bighorn sheep, Ovis canadensis, affects growth of males but not of females. Behav. Ecol. 5, 21-27

204. D. E. Olazabal, M. Villagran, S. X. Gonzalez-Pensado, R. Ungerfeld, Maternal behavior and early development of pampas deer (Ozotoceros bezoarticus) fawns in a semi-captive environment. J. Ethol. 31, 323-330 (2013). 
205. R. Ungerfeld et al., Reproductive biology of the pampas deer (Ozotoceros bezoarticus): a review. Acta Vet. Scand. 50 (2008).

206. T. Furuichi et al., in Long-term field studies of primates. P. M. Kappeler, D. P. Watts, Eds., (Springer-Verlag, Berlin Heidelberg, 2012), pp. 413-433.

207. J. Goodall, The chimpanzees of Gombe: patterns of behaviour. (Harvard University Press, Cambridge, 1996).

720 208. S. W. Townsend, K. E. Slocombe, M. E. Thompson, K. Zuberbuhler, Female-led infanticide in wild chimpanzees. Curr. Biol. 17, R355-R356 (2007).

209. C. Packer, A. E. Pusey, in Infanticide: comparative and evolutionary perspectives, G. Hausfater, S. B. Hrdy, Eds. (Aldine, New York, 1984), pp. 31-42.

210. T. N. Soares et al., Paternity testing and behavioral ecology: A case study of jaguars (Panthera onca) in Emas National Park, Central Brazil. Genetics Mol. Biol. 29, 735-740 (2006).

211. S. K. Wasser, A. K. Starling, in Primate ontogeny, cognition and social behavior, J. G. Else, P. C. Lee, Eds. (Cambridge University Press, Cambridge, 1986), pp. 343354.

730 212. R. A. Palombit, in Sexual Selection and Reproductive Competition in Primates: New Perspectives and Directions, C. B. Jones, Ed. (American Society of Primatologists, 2003), pp. 367-412.

213. C. Brain, Deaths in a desert baboon troop. Int. J. Primatol. 13, 593-599 (1992).

214. S. W. Margulis, M. Nabong, G. Alaks, A. Walsh, R. C. Lacy, Effects of early experience on subsequent parental behaviour and reproductive success in oldfield mice, Peromyscus polionotus. Anim. Behav. 69, 627-634 (2005).

215. D. W. Foltz, Genetic evidence for long-term monogamy in a small rodent, Peromyscus polionotus. Am. Nat. 117, 665-675 (1981).

216. M. J. Somers, O. A. E. Rasa, B. L. Penzhorn, Group structure and social behaviour of warthogs Phacochoerus aethiopicus. Acta Theriol. 40, 257-281 (1995).

217. S. G. Rhind, Reproductive demographics among brush-tailed phascogales (Phascogale tapoatafa) in south-western Australia. Wildlife Research 29, 247-257 (2002).

218. J. Thomas, V. Pastukhov, R. Elsner, E. Petrov, Phoca sibirika - Baikal seal. Mammal. Species 72, 1-6 (1982).

219. B. J. Marlowe, The comparative behaviour of the Australasian sea lions Neophoca cinerea and Phocarctos hookeri (Pinnipedia: Otariidae). Mammalia 39, 159-230 (1975).

220. I. S. Wilkinson, S. J. Childerhouse, P. J. Duignan, F. M. D. Gulland, Infanticide and cannibalism in the New Zealand sea lion, Phocarctos hookeri. Mar. Mammal Sci. 16, 494-500 (2000).

221. K. M. Bohn, C. F. Moss, G. S. Wilkinson, Pup guarding by greater spear-nosed bats. Behav. Ecol. Sociobiol. 63, 1693-1703 (2009).

222. M. A. Norconk, Long-term study of group dynamics and female reproduction in

223. L. H. Beaudrot, S. M. Kahlenberg, A. J. Marshall, Why male orangutans do not kill infants. Behav. Ecol. Sociobiol. 63, 1549-1562 (2009).

224. R. W. Kays, \& Gittleman, J. L., The social organization of the kinkajou Potos flavus (Procyonidae). J. Zool. 253, 491-504 (2001).

760 225. R. Steenbeek, in Infanticide by males and its implications, C. P. Van Schaik, C. H. Janson, Eds. (Cambridge University Press, Cambridge, 2000), pp. 153-177.

226. T. T. Struhsaker, L. Leland, Infanticide in a patrilineal society of red colobus monkeys. Z. Tierpschychologie 69, 89-132 (1985). 
227. P. M. Wright, Demography and life history of free-ranging Propithecus diadema edwardsi at Ranomafana National Park, Madagascar. Int. J. Primatol. 16, 835-853 (1995).

228. E. M. Erhart, D. J. Overdorff, Infanticide in Propithecus diadema edwardsi: An evaluation of the sexual selection hypothesis. Int. J. Primatol. 19, 73-81 (1998).

229. T. Morelli, The rules of disengagement: takeovers, infanticide, and dispersal in a rainforest lemur, Propithecus edwardsi. Behaviour 146, 499-523 (2009).

230. R. Kotze et al., Temporal patterns of den use suggest polygamous mating patterns in an obligate monogamous mammal. Anim. Behav. 84, 1573-1578 (2012).

231. G. Mourao, L. Carvalho, Cannibalism among giant otters (Pteronura brasiliensis). Mammalia 65, 225-227 (2001).

775 232. T. H. Kunz, L. A. Ebensperger, Why does infanticide seem so rare in bats? Acta Chiropt. 1, 17-29 (1999).

233. Z.-F. Xiang, C. C. Grueter, First direct evidence of infanticide and cannibalism in wild snub-nosed monkeys (Rhinopithecus bieti). Am. J. Primatol. 69, 249-254 (2007).

780 234. S. Zhang, L. Bing, L. Wang, Infanticide within captive groups of Sichuan golden snub-nosed monkeys (Rhinopithecus roxellana). Folia Primatol. 70, 274-276 (1999).

235. X. G. Qi, B. G. Li, P. A. Garber, W. Ji, K. Watanabe, Social dynamics of the golden snub-nosed monkey (Rhinopithecus roxellana): female transfer and onemale unit succession. Am. J. Primatol. 71, 670-679 (2009).

236. C. Schradin, N. Pillay, Paternal care in the social and diurnal striped mouse (Rhabdomys pumilio): laboratory and field evidence. J. Comp. Psych. 117, 317-323 (2003).

237. E. Dinerstein, C. Wemmer, H. Mishra, Adoption in greater one-horned rhinoceros (Rhinoceros unicornis). J. Mammal. 69, 813-814 (1988).

238. G. B. Rathbun, Rhynchocyon chrysopygus. Mammal. Species 117, 1-4 (1979).

239. E. Tirado-Herrera, C. Knogge, E. W. Heymann, Infanticide in a group of wild saddle-back tamarins, Saguinus fuscicollis. Am. J. Primatol. 50, 153-157 (2000).

240. L. Culot et al., Reproductive failure, possible maternal infanticide, and cannibalism in wild moustached tamarins, Saguinus mystax. Primates 52, 179-186 (2011).

241. A. Savage, L. H. Giraldo, L. H. Soto, C. T. Snowdon, Demography, group composition, and dispersal in wild cotton-top tamarin (Saguinus oedipus) groups. Am. J. Primatol. 38, 85-100 (1996).

242. H. S. Zimbler-DeLorenzo, A. I. Stone, Integration of field and captive studies for understanding the behavioral ecology of the squirrel monkey (Saimiri sp.). Am. J. Primatol. 73, 607-622 (2011).

243. S. B. Hrdy, Care and exploitation of nonhuman primate infants by conspecifics other than the mother. Adv. Study Behav. 6, 101-158 (1976).

244. J. E. Lane, S. Boutin, M. R. Gunn, J. Slate, D. W. Coltman, Female multiple mating and paternity in free-ranging North American red squirrels. Anim. Behav. 75, 1927-1937 (2008).

245. Y. Sugiyama, in Social communication among primates, S. A. Altmann, Ed. (University of Chicago Press, Chicago, 1967), pp. 221-236.

$810 \quad$ Zool. 239, 525-543 (1996).

247. T. H. Clutton-Brock et al., Infanticide and expulsion of females in a cooperative mammal. Proc. R. Soc. B 265, 2291-2295 (1998). 
248. A. Andersson, A. Valros, J. Rombin, P. Jensen, Extensive infanticide in enclosed European wild boars (Sus scrofa). Appl. Anim. Behav. Science 134, 184-192 (2011).

249. L. Morino, Doctoral dissertation, Rutgers University-Graduate School-New Brunswick (2012).

250. P. Bergeron, D. Reale, M. M. Humphries, D. Garant, Evidence of multiple paternity and mate selection for inbreeding avoidance in wild eastern chipmunks. $J$. Evol. Biol. 24, 1685-1694 (2011).

251. L. E. Harding, Trachypithecus cristatus. Mammal. Species 42, 149-165 (2010).

252. Q. Zhao, C. Borries, W. Pan, Male takeover, infanticide, and female countertactics in white-headed leaf monkeys (Trachypithecus leucocephalus). Behav. Ecol. Sociobiol. 65, 1535-1547 (2011).

825 253. I. A. P. Patterson et al., Evidence for infanticide in bottlenose dolphins: an explanation for violent interactions with harbour porpoises? Proc. R. Soc. B 265, 11671170 (1998).

254. G. R. Trapp, D. L. Hallberg, in The wild canids. Van Nostrand-Reinhold Ed., (New York, 1975).

830 255. C. Samson, \& Huot, J., Spatial and temporal interactions between female American black bears in mixed forests of eastern Canada. Can. J. Zool. 79, 633-641 (2001).

256. R. B. Wielgus, F. L. Bunnell, Possible negative effects of adult male mortality on female grizzly bear reproduction. Biol. Cons. 93, 145-154 (2000).

835 257. M. Taylor, T. Larsen, R. E. Schweinsburg, Observations of intraspecific aggression and cannibalism in polar bears (Ursus maritimus). Arctic 38, 303-309 (1985).

258. A. L. Baden, P. C. Wright, E. E. Louis Jr, B. J. Bradley, Communal nesting, kinship, and maternal success in a social primate. Behav. Ecol. Sociobiol., 67, 19391955 (2013).

840 259. E. P. Kruchenkova, M. Goltsman, S. Sergeev, D. W. Macdonald, Is alloparenting helpful for Mednyi Island arctic foxes, Alopex lagopus semenovi? Naturwissenschaften 96, 457-466 (2009).

260. J. F. Kamler, W. B. Ballard, P. R. Lemons, K. Mote, Variation in mating system and group structure in two populations of swift foxes, Vulpes velox. Anim. Behav.

$845 \quad \mathbf{6 8}, 83-88(2004)$.

261. A. M. Kitchen, E. M. Gese, L. P. Waits, S. M. Karki, E. R. Schauster, Multiple breeding strategies in the swift fox, Vulpes velox. Anim. Behav. 71, 10291038(2006).

262. S. Lariviere, Vulpes zerda. Mammal. Species 714, 1-5 (2002).

850 263. J. M. Waterman, The social organization of the Cape ground squirrel (Xerus inauris; Rodentia: Sciuridae). Ethology 101, 130-147 (1995). 
Supplementary Table 4: Data on infanticide occurrence

Species

Acinonyx_jubatus

Acrobates_pygmaeus

Aepyceros_melampus

Aethomys_namaquensis

Ailurus_fulgens

Alces_alces

Alouatta_caraya

Alouatta_guariba

Alouatta_palliata

Alouatta_pigra

Alouatta_seniculus

Antechinus_stuartii

Antechinus_swainsonii

Antilocapra_americana

Antrozous_pallidus

Aotus_azarae

Arctocephalus_forsteri

Arctocephalus_galapagoensis

Arctocephalus_gazella

Arctocephalus_pusillus

Arctocephalus_tropicalis

Ateles_belzebuth

Ateles_geoffroyi

Ateles_paniscus
MaleInfanticide

No

No

No

Yes

No

No

Yes

Yes

Yes

Yes

Yes

No

No

No

No

No

No

No

No

No

No

Yes

Yes

No
Reference

47

48

49

50

51

52

4

53

4

54,55

4

56

65

$16,57,58$

59

60,61

62

63

64, 65

66

67

68

68, 69

70,71 
Avahi_laniger No

Bison bison

No

$16,73,74$

Brachyteles_arachnoides

No

75

Brachyteles_hypoxanthus

No

76

Bunopithecus_hoolock

Yes

77,79

Callimico_goeldii

No

Callithrix_flaviceps

No

80,81

Callithrix_jacchus

No

81

Callorhinus_ursinus

No

4

Canis_dingo

No

82

Canis_latrans

No

4,16

Canis_lupus

No

16,83

Canis_mesomelas

No

16,84

Canis_simensis

No

16,85

Capreolus_capreolus

No

86

Cavia_aperea

No

4, 87

Cavia_intermedia

No

4

Cavia_magna

No

4, 88

Cavia_porcellus

No

4,89

Cebus_apella

Yes

Cebus_capucinus

Yes

91

Cebus nigritus

Yes

92

Cebus_olivaceus

Yes

4

Cercocebus_atys

Yes

4, 16

Cercocebus_galeritus

Yes

16

Cercocebus_torquatus

Yes

$16,93,94$

Cercopithecus_albogularis

No 
Cercopithecus_ascanius

Yes

4

Cercopithecus_campbelli

Yes

96

Cercopithecus_mitis

Yes

4

Cervus_elaphus

No

97

Chalinolobus_gouldii

No

98

Cheirogaleus_medius

No

99,100

Chiropotes_albinasus

No

101

Chiropotes_satanas

No

101

Chlorocebus_aethiops

Yes

102,103

Colobus_guereza

Yes

4

Colobus_vellerosus

Yes

12

Connochaetes taurinus

No

104

Crocidura_russula

No

105

Crocuta_crocuta

No

106

Cuon_alpinus

No

107

Cynictis_penicillata

No

108

Cynomys_gunnisoni

No

7

Cynomys_leucurus

No

109

Cynomys_ludovicianus

Yes

7

Cynomys_parvidens

Yes

110

Cynopterus_brachyotis

Yes

111

Cystophora_cristata

No

112

Dasyurus_hallucatus

No

113

Dasyurus_viverrinus

No

113

Diceros_bicornis

No

114

Dicrostonyx_groenlandicus

Yes

7

Didelphis_virginiana

No

115 
Dolichotis_patagonum

Enhydra_lutris

Yes

117

Eptesicus_fuscus

No

118

Equus_caballus

Yes

Equus_zebra

Yes

119,120

Erythrocebus_patas

Yes

121

Eubalaena_australis

No

122

Eulemur_fulvus

Yes

123

Eulemur_macaco

Yes

123,124

Eumetopias_jubatus

No

125

Felis_catus

Yes

126

Galea_monasteriensis

No

127

Gazella_dorcas

No

128

Giraffa_camelopardalis

No

129,130

Gorilla_beringei

Yes

Gorilla_gorilla

Yes

131

Halichoerus_grypus

Yes

132

Hapalemur_griseus

No

133

Helogale_parvula

No

134,135

Herpestes_sanguineus

No

136,137

Heterocephalus_glaber

No

138

Hippopotamus_amphibius

Yes

139

Hippotragus_equinus

No

140

Hyaena_brunnea

No

141

Hyaena_hyaena

No

142,143

Hylobates_lar

Yes

14

Lagothrix_lagotricha

No

144,145 
Lasiopodomys_brandtii

Lemur_catta

Leontopithecus_rosalia

Leopardus_pardalis

Lepilemur_edwardsi

Leptonychotes_weddellii

Lepus_americanus

Lophocebus_albigena

Lophostoma_silvicolum

Loris_lydekkerianus

Loris_tardigradus

Loxodonta_africana

Lycaon_pictus

Lynx_canadensis

Lynx_pardinus

Macaca_arctoides

Macaca_fascicularis

Macaca_mulatta

Macaca_nemestrina

Macaca_nigra

Macaca_radiata

Macaca_silenus

Macaca_sinica

Macaca_sylvanus

Macaca_thibetana

Macaca_tonkeana

Macropus_giganteus
Yes

Yes

No

123,146

Yes 147

47

Yes

148

No

149

No

150

No

151

Yes

152

No

153,154

No

153,155

No

No

156,157

158

Yes

47

Yes

159

Yes

160

Yes

4

Yes

161

Yes

16

Yes

16

Yes

4

Yes

16

Yes

162

Yes

4

Yes

163

No

164

No 
Madoqua_kirkii

No

166

Mandrillus_sphinx

Yes

167

Marmota_caligata

Yes

110

Marmota_caudata

Yes

Marmota_flaviventris

No

Marmota_marmota

Yes

4

Marmota_monax

No

168

Martes_americana

No

169

Martes_pennanti

No

169

Megaderma_lyra

No

152

Meles_meles

No

4

Mellivora_capensis

Yes

171

Mephitis_mephitis

Yes

172

Microcebus_murinus

No

173,174

Microtus_arvalis

Yes

175

Microtus_canicaudus

No

Microtus_pennsylvanicus

Yes

110

Microtus_townsendii

No

Mirounga_angustirostris

Yes

176,177

Mirounga_leonina

Yes

178

Monachus_schauinslandi

Yes

179,180

Mungos_mungo

No

181

Mustela erminea

No

182

Mustela_frenata

Yes

16

Myodes_glareolus

Yes

110

Myotis_myotis

No

183

Nasalis_larvatus

Yes

184 
Nasua_nasua

Neophoca_cinerea

Neotoma_albigula

Neotoma_cinerea

Neotoma_lepida

Neovison_vison

Nyctereutes_procyonoides

Ochotona_curzoniae

Octodon_degus

Odobenus_rosmarus

Odocoileus_virginianus

Onychomys_torridus

Oreamnos_americanus

Oryctolagus_cuniculus

Oryx_leucoryx

Otaria_byronia

Otocyon_megalotis

Ovibos_moschatus

Ovis_aries

Ovis_canadensis

Ozotoceros_bezoarticus

Pan_paniscus

Pan_troglodytes

Panthera_leo

Panthera_onca

Panthera_pardus

Panthera_tigris
Yes

4

Yes 185

No 186

No

No

Yes

No

No

No

No

No

No

No

No

Yes

Yes

No

No

No

No

No

No

Yes

Yes

Yes

Yes

Yes
187

7

188

189-191

192

193

194

195

196

197

198

199

200

201

202

197

203

204, 205

206

207, 208

209

210

47

47 
Papio_anubis

Yes

4

Papio_cynocephalus

Yes

211

Papio_hamadryas

Yes

211

Papio_ursinus

Yes

4,213

Paraxerus_cepapi

Yes

7

Peromyscus_leucopus

Yes

7

Peromyscus_maniculatus

Yes

7

Peromyscus_polionotus

No

214,215

Phacochoerus_aethiopicus

No

216

Phascogale_tapoatafa

No

217

Phoca_groenlandica

No

194

Phoca_sibirica

No

218

Phoca_vitulina

No

194

Phocarctos_hookeri

Yes

219,220

Phodopus_sungorus

Yes

7

Phyllostomus_hastatus

No

221

Pithecia pithecia

No

222

Pongo_abelii

No

223

Pongo_pygmaeus

No

223

Potos_flavus

No

224

Presbytis_potenziani

No

71

Presbytis_thomasi

Yes

225

Procolobus_badius

Yes

226

Propithecus_diadema

Yes

227,228

Propithecus edwardsi

Yes

4, 229

Propithecus_verreauxi

Yes

16

Proteles_cristata

No

230 
Pteronura_brasiliensis

Pteropus_hypomelanus

Pteropus_vampyrus

Puma_concolor

Pygathrix_bieti

Pygathrix_roxellana

Rangifer_tarandus

Rhabdomys_pumilio

Rhinoceros_unicornis

Rhynchocyon_chrysopygus

Saguinus_fuscicollis

Saguinus_mystax

Saguinus_oedipus

Saimiri_oerstedii

Saimiri_sciureus

Sciurus_carolinensis

Semnopithecus_entellus

Speothos_venaticus

Spermophilus_beecheyi

Spermophilus_beldingi

Spermophilus_columbianus

Spermophilus_franklinii

Spermophilus_parryii

Spermophilus_richardsonii

Spermophilus_townsendii

Spermophilus_tridecemlineatus

Suricata_suricatta
Yes

231

No

232

No

232

Yes

Yes

233

Yes

No

234, 235

Yes

197

236

Yes

237

No

238

No

239

No

240

No

241

No

242

Yes

243

Yes

244

Yes

245

No

246

No

4

Yes

110

Yes

7

Yes

Yes

No

Yes

Yes

No

7

.


Sus_scrofa

Symphalangus_syndactylus

Tadarida_brasiliensis

Tamias_striatus

Theropithecus_gelada

Trachypithecus_cristatus

Trachypithecus_poliocephalus

Trachypithecus_vetulus

Tursiops_truncatus

Urocyon_cinereoargenteus

Ursus_americanus

Ursus_arctos

Ursus_maritimus

Varecia_variegata

Vulpes_lagopus

Vulpes_velox

Vulpes_vulpes

Vulpes_zerda

Xerus_inauris

Zalophus_californianus
No

248

Yes

249

No

No

Yes

Yes

Yes

Yes

Yes

No

Yes

Yes

Yes

Yes

Yes

No

No

No

No

No
111,152 250

4 251 252

4 253 254

4, 255

4, 256

257

258

259

260, 261

209

262

263

194 